\title{
High-Performance Ultrathin Flexible Solid-State Supercapacitors Based on Solution Processable Mo1.33C MXene and PEDOT:PSS
}

Qin Leiqiang, Quanzheng Tao, Ahmed El Ghazaly, Julia Fernandez-Rodriguez, Per OA Persson, Johanna Rosén and Fengling Zhang

The self-archived postprint version of this journal article is available at Linköping University Institutional Repository (DiVA):

http://urn.kb.se/resolve?urn=urn:nbn:se:liu:diva-144437

N.B.: When citing this work, cite the original publication.

Leiqiang, Q., Tao, Q., El Ghazaly, A., Fernandez-Rodriguez, J., Persson, P. OA, Rosén, J., Zhang, F., (2018), High-Performance Ultrathin Flexible Solid-State Supercapacitors Based on Solution Processable Mo1.33C MXene and PEDOT:PSS, Advanced Functional Materials, 28(2), .

https://doi.org/10.1002/adfm.201703808

Original publication available at:

https://doi.org/10.1002/adfm.201703808

Copyright: Wiley (12 months)

http://eu.wiley.com/WileyCDA/ 


\section{WILEY-VCH}

DOI: 10.1002/((please add manuscript number))

Article type: Full Paper

High-Performance Ultrathin Flexible Solid-State Supercapacitors based on Solution Processable Mo1.33C MXene and PEDOT:PSS

Leiqiang Qin, Quanzheng Tao, Ahmed El Ghazaly, Julia Fernández-Rodríguez, Per O. A. Persson, Johanna Rosen* and Fengling Zhang*

Dr. L. Qin, Mr. Q. Tao, Mr. A. E. Ghazaly, Prof. P. O. Å. Persson, Prof. J. Rosen, Prof. F. Zhang

Department of Physics, Chemistry and Biology (IFM), Linköping University, SE-581 83 Linköping, Sweden

Prof. J. Fernández-Rodríguez

Centre for Cellular Imaging, Sahlgrenska Academy, University of Gothenburg, SE-405 30, Gothenburg, Sweden

E-mail: johanna.rosen@liu.se; fengling.zhang@liu.se

L. Qin and Q. Tao contributed equally to this work.

Keywords: solid-state supercapacitor, MXene, Mo1.33C, PEDOT:PSS, composite film

MXenes, a young family of two-dimensional (2D) transition metal carbides/nitrides, show great potential in electrochemical energy storage applications. Herein, a high performance ultra-thin flexible solid-state supercapacitor is demonstrated based on a $\mathrm{Mo}_{1.33} \mathrm{C}$ MXene with vacancyordering in an aligned layer structure MXene/PEDOT:PSS composite film post-treated with concentrated $\mathrm{H}_{2} \mathrm{SO}_{4}$. The flexible solid-state supercapacitor delivers a maximum capacitance of $568 \mathrm{~F} \mathrm{~cm}^{-3}$, an ultrahigh energy density of $33.2 \mathrm{mWh} \mathrm{cm}^{-3}$ and a power density of 19470 $\mathrm{mW} \mathrm{cm}^{-3}$. The $\mathrm{Mo}_{1.33} \mathrm{C}$ MXene/PEDOT:PSS composite film shows a reduction in resistance upon $\mathrm{H}_{2} \mathrm{SO}_{4}$ treatment, a higher capacitance $\left(1310 \mathrm{~F} \mathrm{~cm}^{-3}\right)$ and improved rate-capabilities than both pristine $\mathrm{Mo}_{1.33} \mathrm{C}$ MXene and the non-treated Mo1.33 C/PEDOT:PSS composite films. The enhanced capacitance and stability are attributed to the synergistic effect of increased interlayer 


\section{WILEY-VCH}

spacing between $\mathrm{Mo}_{1.33} \mathrm{C}$ MXene layers due to insertion of conductive PEDOT, and surface redox processes of the PEDOT and the MXene.

\section{Introduction}

With the fast growing demand for portable and wearable electronic devices, flexible lightweight high-performance energy storage devices are urgently needed. ${ }^{[1]}$ Among various energy storage devices, supercapacitors have attracted tremendous attention due to their outstanding features, such as high power density, ultra-fast charge and discharge rate, low maintenance, long cycle life, excellent stability and safe operation. These features make supercapacitors promising candidates for the next generation of energy storage applications such as portable electronics, power back-up systems and hybrid vehicles. ${ }^{[2]}$ Based on their charge storage mechanisms, supercapacitors can be divided into two groups; electric double-layer capacitors (EDLCs), where the charge is stored via electrosorption of ions, or pseudocapacitors, where surface redox reactions enable charge storage. ${ }^{[3]}$ Current limitation of commercially available supercapacitors is an energy density much lower than those of batteries and fuel cells, which is a hot research topic in search the next generation of energy storage devices. One strategy to increase the energy density of supercapacitors is to use pseudocapacitive materials, such as metal oxides or electrochemically active organic molecules/polymers as electrodes. ${ }^{[4]}$

In the past decade, 2D materials have been extensively studied for diverse applications due to their excellent electronic, mechanical and optical properties. ${ }^{[5]}$ One example is MXenes, a young family of 2D transition metal carbides, carbonitride and nitrides with metallic conductivity and hydrophilic surfaces. They are produced by selective etching of the A layers in the atomically laminated $\mathrm{M}_{\mathrm{n}+1} \mathrm{AX}$ n phases, ${ }^{[6]}$ where $\mathrm{M}$ is a transition metal, $\mathrm{A}$ is an A-group element (mostly $\mathrm{Al}$ ), and $\mathrm{X}$ is $\mathrm{C}$ and/or $\mathrm{N}$. MXenes have already shown great potential for applications in $\mathrm{Li}$-ion batteries, ${ }^{[7]} \mathrm{Li}-\mathrm{S}$ batteries, ${ }^{[8]}$ metal ion capacitors, ${ }^{[9]}$ and aqueous supercapacitors. ${ }^{[10]}$ An increased MXene surface area upon delamination of the multilayered 


\section{WILEY-VCH}

MXenes into single- or few-layer nanosheets, together with a pseudocapacitive charge storage mechanism and a high conductivity, gives capacitance values outperforming carbon electrodes.

Most recently, we reported a route for synthesis of vacancy-ordered Mo ${ }_{1.33} \mathrm{C}$ MXene, with a resulting capacitance of $1153 \mathrm{~F} \mathrm{~cm}^{-3}$, and a higher conductivity of $29674 \mathrm{~s} \mathrm{~m}^{-1}$ for a MXene film. ${ }^{[11]}$ Furthermore, previous research have shown that an improved charge transport in MXene supercapacitor electrodes can be facilitated by an increase in the interlayer spacing of $\mathrm{Ti}_{3} \mathrm{C}_{2} \mathrm{~T}_{\mathrm{x}}$ MXene by using intercalation of a polymer (PVA and PDDA). ${ }^{[12]}$ In addition, the structure of the macroporous electrode was constructed by using MXene hydrogel enable exceptional high-rate performance by fast ion transport and reaching the highest volumetric capacitance of $\sim 1500 \mathrm{~F} \mathrm{~cm}^{-3}{ }^{[13]}$ In the light of these promising results, attention is directed towards poly(3,4-ethylenedioxythiophene):poly(styrenesulfonic acid) (PEDOT:PSS) (Scheme S1), one of the most widely used solution processable conducting polymers, shown to be of great significance for both fundamental research and commercial applications. PEDOT prepared by electrochemical polymerization or chemical oxidation is insoluble and difficult for solution processing. To make PEDOT soluble, PSS is added as a surfactant and dopant to promote the suspension of PEDOT in aqueous solutions. In addition, the complex of PEDOT:PSS possesses outstanding advantages of excellent solution processing properties, good film-forming properties, high flexibility, and excellent thermal stability, especially the tunable and improved conductivity achieved by physical or chemical treatment. It is also worth noting that the conductivity of PEDOT:PSS can reach a maximum value of $4380 \mathrm{~S} \mathrm{~cm}^{-1}$ via $\mathrm{H}_{2} \mathrm{SO}_{4}$ post-treatment, four orders of magnitude larger than untreated PEDOT:PSS films, which is impossible for pure PEDOT. ${ }^{[14]}$ Therefore, PEDOT:PSS is the most widely studied conducting polymer as a supercapacitor material for its high stability, high conductivity in the doped state, and its fast redox protonation/deprotonation reactions. Combining the outstanding properties of the MXene and the polymer suggests a potential unique electrode architecture of 


\section{WILEY-VCH}

improved stability and elasticity for solution processed flexible high performance stable solidstate supercapacitors.

To date, the few reports about MXene and polymer composites are limited to the evaluation of electrode materials for supercapacitor applications, and the composites have not yet been applied to devices. ${ }^{[15]}$ Herein, we demonstrate high performance ultra-thin solid-state supercapacitors based on flexible aligned $\mathrm{Mo}_{1.33} \mathrm{C}$ MXene/PEDOT:PSS composite films obtained from solution processable Mo ${ }_{1.33} \mathrm{C}$ MXene and PEDOT:PSS hybrid ink followed by immersion in concentrated $\mathrm{H}_{2} \mathrm{SO}_{4}$ solutions for 24 hours. The representative flexible solid-state supercapacitor exhibits a capacitance up to $568 \mathrm{~F} \mathrm{~cm}^{-3}$, an ultrahigh energy density of 33.2 $\mathrm{mWh} \mathrm{cm}^{-3}$, an excellent cycling stability and outstanding deformation tolerance due to intercalating conductive PEDOT:PSS chains in the MXene/PEDOT:PSS composite films.

\section{Results and Discussion}

The procedures for preparing the composite films and fabricating the solid-state supercapacitors are schematically illustrated in Figure 1 (see details in the Experimental Section). In order to get the optimal Mo ${ }_{1.33} \mathrm{C}$ MXene to PEDOT:PSS ratio, a series of flexible composite films are obtained by vacuum filtration of the Mo ${ }_{1.33} \mathrm{C}$ MXene and PEDOT:PSS dispersion in mass ratios of $50: 1,20: 1,10: 1,5: 1,2: 1,1: 1,1: 2$, and 1:5. Hereafter the flexible composite films will be referred as M:P (50:1, 20:1, 10:1, 5:1, 2:1, 1:1, 1:2, 1:5). Pure Mo1.33 C MXene and pure PEDOT:PSS "papers" are also prepared for comparison. The electrochemical properties of the different as-fabricated composite electrodes are first inspected using cyclic voltammetry (CV) experiments in $1 \mathrm{M} \mathrm{H}_{2} \mathrm{SO}_{4}$ at various sweep rates in the potential window from -0.35 to $0.3 \mathrm{~V}$ vs. Ag/AgCl (Figure S1). The volumetric capacitances of ten different composite electrodes are summarized in Table 1 where the pristine $\mathrm{Mo}_{1.33} \mathrm{C}$ film exhibits the highest volumetric capacitance of $1187 \mathrm{~F} \mathrm{~cm}^{-3}$ (at $2 \mathrm{mV} / \mathrm{s}$ ), followed by $1095 \mathrm{~F} \mathrm{~cm}^{-3}$ for 20:1, $949 \mathrm{~F} \mathrm{~cm}^{-3}$ for $10: 1$, 939 for 50:1 and then a monotonically decrease with increasing the loading of PEDOT:PSS. 


\section{WILEY-VCH}

To increase the conductivity of PEDOT:PSS in the composite films, all samples are immersed into concentrated $\mathrm{H}_{2} \mathrm{SO}_{4}$ for 24 hours as reported in the literature. ${ }^{[14]}$ Encouragingly, significantly improved conductivity and electrochemical properties are observed for the treated composite films (Figure S2). Notably, the $\mathrm{H}_{2} \mathrm{SO}_{4}$ treated composite electrode with a mass ratio of 10:1 (referred to as $\mathrm{M}: \mathrm{P}=10: 1-24 \mathrm{~h}$ ) exhibits a maximum volumetric capacitance of $1310 \mathrm{~F}$ $\mathrm{cm}^{-3}$ (2 $\mathrm{mV} \mathrm{s}^{-1}, 452 \mathrm{~F} \mathrm{~g}^{-1}$ ), which is superior to the literature reports on MXene based electrodes. ${ }^{[6,9,10]}$ Consequently, this investigation is from this point forward focused on the $\mathrm{M}: \mathrm{P}=10: 1-24 \mathrm{~h}$ films. The pristine $\mathrm{Mo}_{1.33} \mathrm{C}$ films and $\mathrm{M}: \mathrm{P}=10: 1$ (without $\mathrm{H}_{2} \mathrm{SO}_{4}$ posttreatment) will also be investigated for reference. To study the effect of PEDOT:PSS and $\mathrm{H}_{2} \mathrm{SO}_{4}$ treatment on the capacitance of the MXene films, the capacitances of the three electrodes $\left(\mathrm{Mo}_{1.33} \mathrm{C}, \mathrm{M}: \mathrm{P}=10: 1\right.$ and $\left.\mathrm{M}: \mathrm{P}=10: 1-24 \mathrm{~h}\right)$ are recorded by $\mathrm{CV}$ at the scan rate of 2 $\mathrm{mV} \mathrm{s}^{-1}$. It is clear that the $\mathrm{M}: \mathrm{P}=10: 1-24 \mathrm{~h}$ has the highest capacitance, while $\mathrm{M}: \mathrm{P}=10: 1$ has the lowest capacitance, see Figure 2A. The reduced capacitance of $\mathrm{M}: \mathrm{P}=10: 1$ may be attributed to the known electrochemically inactivity of PSS in the PEDOT:PSS. This is supported by Table 1, showing that increasing PEDOT:PSS loading results in a decline in capacitances due to electrochemical inactivity and poor conductivity of PSS. As previously reported, ${ }^{[14]}$ when the composite electrodes are treated with concentrated $\mathrm{H}_{2} \mathrm{SO}_{4}$, the dense PEDOT networks will be significant changed in both the crystallographic and morphological structures via the formation of crystalline nanofibril structures. This is accompanied by excess uncoupled PSS being removed. ${ }^{[14,16]}$ In the present work a significant removal of the PSS content is confirmed by FT-IR and absorption spectra (Figure S3). Interaction between the presumed negatively charged $\mathrm{Mo}_{1.33} \mathrm{C}$ Mxene $^{[17]}$ and the positively charged PEDOT is expected, which in turn is likely to influence charge transport as well as charge storage capabilities. Furthermore, the PEDOT nanofibril network enlarges the interlayer spacing between the MXene flakes and likely facilitate efficient intra- and inter-chain charge transport, potentially also increasing the accessibility to deep traps, which may enhance the net capacitances of the composite electrodes. 


\section{WILEY-VCH}

The nearly triangular galvanostatic charge/discharge curves, see Figure $2 \mathrm{~B}$, of the $\mathrm{M}: \mathrm{P}=10: 1$ 24h composite film at different current densities confirm the high reversibility of the redox reactions and good coulomb efficiency ( $96 \%$ ) of the tested electrodes. A comparison of the rate performance of the $\mathrm{M}: \mathrm{P}=10: 1$ composite film with pristine $\mathrm{Mo}_{1.33} \mathrm{C}$ is presented in Figure 2C. The volumetric capacitance of the $\mathrm{M}: \mathrm{P}=10: 1-24 \mathrm{~h}$ is higher than the untreated composite film and the pristine $\mathrm{Mo}_{1.33} \mathrm{C}$ at various sweep rates. In addition, the post-treated composite film shows a good rate performance. Even at a scan rate of $1000 \mathrm{mV} \mathrm{s}^{-1}$, it yields a high capacitance of $589 \mathrm{~F} \mathrm{~cm}^{-3}$. This may be due to dual redox contributions from the MXene and the PEDOT, and the aligned PEDOT nanofibril network between the metallic $\mathrm{Mo}_{1.33} \mathrm{C}$ layers providing conductive channels for facile ionic transport. Electrochemical impedance spectroscopy was performed to study the charge transfer resistance $\left(\mathrm{R}_{\mathrm{ct}}\right)$ and ion transport in the tested electrodes. Nyquist plots, see Figure 2D, confirms fast ion transport in the $M: P=10: 1-$ 24h composite film. At low frequency, a large slope close to $90^{\circ}$ is present in all films, which may be attributed to the highly accessible surface of the layer-stacked film. Furthermore, in the high-frequency region, the $\mathrm{M}: \mathrm{P}=10: 1-24$ h composite film shows a quite small charge transport resistance with an invisible semicircle, emphasizing the superiority of the composite films.

For structural characterization, the cross-sections of the three films $\left(\mathrm{Mo}_{1.33} \mathrm{C}, \mathrm{M}: \mathrm{P}=10: 1\right.$ and $\mathrm{M}: \mathrm{P}=10: 1-24 \mathrm{~h})$ are imaged by scanning electron microscopy (SEM) and shown in Figure 3. The pristine $\mathrm{Mo}_{1.33} \mathrm{C}$ film exhibits the well-aligned stacked MXene sheets (Figure 3A), and maintains a good layered structure after treated by concentrated $\mathrm{H}_{2} \mathrm{SO}_{4}$ (Figure S4). The $\mathrm{M}: \mathrm{P}=10: 1$ composite film display a less clear layer stacking (Figure 3B). This can be attributed to different mechanical properties, resulting in a different appearance upon breaking the paper. The laminated structure is, however, again evident after $\mathrm{H}_{2} \mathrm{SO}_{4}$ treatment (Figure 3C). The Xray diffraction (XRD) patterns (Figure 3D) of the $\mathrm{M}: \mathrm{P}=10: 1$ composite film shows a major peak at $8^{\circ}$, which originates from the $\mathrm{Mo}_{1.33} \mathrm{C}$ MXene. For the $\mathrm{M}: \mathrm{P}=10: 1$ sample it can be assumed that stacks of a few layer Mo ${ }_{1.33} \mathrm{C}$ MXene sheets are interleaved with a polymer layer, where 


\section{WILEY-VCH}

the latter is indicated from the bumps at $\sim 5^{\circ}$ and $\sim 26^{\circ}$. The treated $\mathrm{M}: \mathrm{P}=10: 1-24 \mathrm{~h}$ film exhibit a clear downshift in the (001) peak from $\sim 8.4^{\circ}$ to $\sim 6.8^{\circ}$, indicating an increase of $\approx 2.4 \AA$ in the spacing between the $\mathrm{Mo}_{1.33} \mathrm{C}$ sheets. This shift is attributed to water and/or polymer intercalation in $\mathrm{Mo}_{1.33} \mathrm{C}$ MXenes. ${ }^{[18]}$ However, the previously shown crystallographic structures of the PEDOT after treatment (Figure S5) cannot be distinguished by XRD. Transmission Electron microscopy (TEM) results confirm the laminated microstructure of $\mathrm{M}: \mathrm{P}=10: 1-24 \mathrm{~h}$ as shown in SEM. Figure 3E shows a cross sectional image (top to bottom) of the $\mathrm{M}: \mathrm{P}=10: 1-24 \mathrm{~h}$. The higher magnification image of the layered structure in Figure 3F reveals that the $\mathrm{Mo}_{1.33} \mathrm{C}$ MXene sheets (dark lines) appear to be separated into individual 2D sheets. Ignoring local disturbances, somewhat regular interplanar spaces of the sheets can be observed, as caused by the conductive polymer (bright lines).

In an evaluation of mechanical properties, the nanohardness $(\mathrm{H})$ and Young`s modulus $(\mathrm{E})$ of the pristine $\mathrm{Mo}_{1.33} \mathrm{C}$ film is found to be $0.47 \pm 0.15 \mathrm{GPa}$ and $6 \pm 1.8 \mathrm{GPa}$, respectively. This can be compared to $\mathrm{Ti}_{3} \mathrm{C}_{2} \mathrm{~T}_{\mathrm{x}}$ MXene, with an $\mathrm{E}$ of $\sim 3 \mathrm{GPa} .{ }^{[11,19]}$ Adding PEDOT:PSS with an $\mathrm{E}$ of $3.3 \pm 0.1 \mathrm{GPa}^{[20]}$, results in a reduction of $\mathrm{H}$ as well as $\mathrm{E}$ to $0.11 \pm 0.006$ and $4.9 \pm 0.17 \mathrm{GPa}$, respectively (Figure S6). A small deviation in the $\mathrm{H}$ and $\mathrm{E}$ values for the composite film illustrate a homogeneous distribution of PEDOT:PSS and Mo1.33C MXene, as confirmed by the TEM analysis.

To further explore the potential of MXene-polymer composite films for energy storage, flexible solid-state supercapacitors are fabricated based on $\mathrm{M}: \mathrm{P}=10: 1-24 \mathrm{~h}$. Similar to the composite films, the corresponding devices show superior mechanical flexibility, and can be bent or twisted without damaging the structure and morphology. The typical thickness of the entire device is $\sim 67 \mu \mathrm{m}$, which is thinner than a commercial standard printer paper. The performance of the all-solid-state supercapacitor is investigated based on CV curves (Figure 4A and Figure 57,8 ). For $\mathrm{M}: \mathrm{P}=10: 1-24 \mathrm{~h}$, the shapes of the $\mathrm{CV}$ curves remained pseudorectangular, even at very high scan rates $\left(1000 \mathrm{mV} \mathrm{s}^{-1}\right)$, which indicates a low resistance 


\section{WILEY-VCH}

and good reversibility. Figure 4B shows the galvanostatic charging/discharging curves of the $\mathrm{M}: \mathrm{P}=10: 1-24 \mathrm{~h}$ device. The near triangular shapes of these curves indicate good reversibility of the charging/discharging process, which is in good agreement with the CV curves shown in Figure 4A. The current density dependence of the volumetric capacitance can be calculated from the discharge curves of the flexible supercapacitor. The capacitance of the device reaches $568 \mathrm{~F} \mathrm{~cm}^{-3}$ at a current density of $0.5 \mathrm{~A} \mathrm{~cm}^{-3}$. Similar to the results from a three-electrode system (Figure 3C), the $\mathrm{M}: \mathrm{P}=10: 1-24 \mathrm{~h}$ device shows superior rate performance compared with supercapacitor devices made from pristine $\mathrm{Mo}_{1.33} \mathrm{C}$ and $\mathrm{M}: \mathrm{P}=10: 1$ (Figure 4C). With a current density increase, the volumetric capacitance of the $\mathrm{M}: \mathrm{P}=10: 1-24 \mathrm{~h}$ device remains high. Even at the highest current density of $30 \mathrm{~A} \mathrm{~cm}^{-3}$, the capacitance is $421.2 \mathrm{~F} \mathrm{~cm}^{-3}$. This outstanding charging/discharging rate stability of the $\mathrm{M}: \mathrm{P}=10: 1-24 \mathrm{~h}$ device may be explained by the aligned layer structure formed by the intercalated PEDOT:PSS nanofibrils between the $\mathrm{Mo}_{1.33} \mathrm{C}$ sheets, which increases the layer spacing and facilitates ion transport between the MXene sheets. To show further the merits of the composite film as the electrode material, the electrochemical impedance spectra (EIS) of devices from $\mathrm{M}: \mathrm{P}=10: 1-24 \mathrm{~h}, \mathrm{M}: \mathrm{P}=10: 1$, and pristine $\mathrm{Mo}_{1.33} \mathrm{C}$ are compared in Figure 4D. It can be seen that the complex plane plots of $\mathrm{M}: \mathrm{P}=10: 1-24 \mathrm{~h}$ and pristine $\mathrm{Mo}_{1.33} \mathrm{C}$ show a larger slope of close to $90^{\circ}$ compared to $\mathrm{M}: \mathrm{P}=10: 1$ at a low frequency, which indicates fast ion diffusion. At the high frequency, see inset, the $\mathrm{M}: \mathrm{P}=10: 1-24 \mathrm{~h}$ shows a smaller charge-transport semicircle than $\mathrm{M}: \mathrm{P}=10: 1$ and pristine $\mathrm{Mo}_{1.33} \mathrm{C}$, which is consistent with the result that the crystalline PEDOT:PSS nanofibril network enhance the conductivity of the composite film upon $\mathrm{H}_{2} \mathrm{SO}_{4}$ treatment.

To demonstrate the application prospects of the composite films of $\mathrm{M}: \mathrm{P}=10: 1-24 \mathrm{~h}$, the devices are directly integrated in series and/or parallel connections to increase the output voltage or total capacitance (Figure 5A and B). Figure 5C shows that an applied voltage of $\approx$ 2.6 V obtained from four integrated all-solid-state supercapacitors in series, can essentially power a LED for tens of seconds. Furthermore, the cycling stability of the fabricated all-solid- 


\section{WILEY-VCH}

state supercapacitors are investigated by galvanostatic charge/discharge tests at the current of 5 $\mathrm{A} \mathrm{cm}^{-3}$ (Figure 5D). After 10000 cycles, the $\mathrm{M}: \mathrm{P}=10: 1-24 \mathrm{~h}$ device exhibit a capacitive retention of $90 \%$, which compares favorably to the $\mathrm{M}: \mathrm{P}=10: 1$ (80\%), and pristine $\mathrm{Mo}_{1.33} \mathrm{C}$ (49\%) device. The latter value can be compared to the previously reported $84 \%$ retained capacitance for a $\mathrm{Mo}_{1.33} \mathrm{C}$ film. ${ }^{[11]}$ The morphology of the $\mathrm{M}: \mathrm{P}=10: 1-24 \mathrm{~h}$ device after 10000 cycles is almost maintaining the aligned structure while the pristine $\mathrm{Mo}_{1.33} \mathrm{C}$ device changed significantly after cycling (Figure S9). Two main reasons for the much improved cycling performance of the posttreated composite electrodes compared with the untreated composite electrodes or pristine $\mathrm{Mo}_{1.33} \mathrm{C}$ electrode are suggested: First, after treatment with concentrated $\mathrm{H}_{2} \mathrm{SO}_{4}$, the PEDOT:PSS nanofibril network will strengthen the composite films and suppress the volume change and counter-ion draining during the charging/discharging process. Second, the $\mathrm{M}: \mathrm{P}=10: 1-24 \mathrm{~h}$ device exhibit lower internal resistance and charge transport resistance, which has been discussed in detail in the EIS discussion part. This means that the $\mathrm{M}: \mathrm{P}=10: 1-24 \mathrm{~h}$ films will display smaller charge loss during long-term cycling, which further increases the cycling stability. Furthermore, the devices based on $\mathrm{M}: \mathrm{P}=10: 1-24 \mathrm{~h}$ shows exceptional electrochemical stability under different bending angles. It is shown that CV curves from different bending angles show nearly the same capacitive behavior (Figure 5E). Also, the devices of $\mathrm{M}: \mathrm{P}=10: 1$ 24h shows lower self-discharge, it is decaying to above $0.35 \mathrm{~V}$ after $100 \mathrm{~h}$ (Figure S11).

Energy density is a critical parameter used to compare different types of energy storage systems, with a high volumetric energy density being particularly important for supercapacitors. The volumetric energy and power densities of the $\mathrm{M}: \mathrm{P}=10: 1-24 \mathrm{~h}$ devices, as well as a comparison with previously reported devices and commercial supercapacitors, are plotted in the Ragone plot in Figure 5F. A maximum energy density of $33.2 \mathrm{mWh} \mathrm{cm}^{-3}$ obtained in $\mathrm{M}: \mathrm{P}=10: 1-24 \mathrm{~h}$ devices is higher than that of most recently reported electric double-layer capacitors or pseudocapacitors. ${ }^{[21]}$ This high energy density is likely due to the dual fast pseudocapacitive behavior of the $\mathrm{Mo}_{1.33} \mathrm{C}$ MXene and the PEDOT:PSS. Also, the M:P=10:1- 


\section{WILEY-VCH}

24h device can maintain a surprisingly high energy density of $24.72 \mathrm{mWh} \mathrm{cm}^{-3}$ at the high power density of $19470 \mathrm{~mW} \mathrm{~cm}^{-3}$. The outstanding performance of the $\mathrm{M}: \mathrm{P}=10: 1-24 \mathrm{~h}$ likely originates from highly conducting $\mathrm{Mo}_{1.33} \mathrm{C}$ MXene sheets with pseudocapacitive charge storage mechanisms being separated by a nanofibril structure from $\mathrm{H}_{2} \mathrm{SO}_{4}$ treated PEDOT:PSS. This, in turn facilitate MXene-PEDOT interaction, which seems to improve charge storage (active surface area) and effectively promote electron and ion transport, both inter- and intra-layer, during the charge/discharge cycle. Finally, the PEDOT network is likely to minimize the volume change and counter-ion draining during the charging/discharging process, which greatly improve the long-term performance of the composite electrodes.

\section{Conclusion}

In summary, we demonstrate an effective strategy to realize a high-performance ultra-thin flexible solid-state supercapacitor by using aligned layer structured composite films as active electrodes, obtained from vacuum filtrated $\mathrm{Mo}_{1.33} \mathrm{C}$ MXene and PEDOT:PSS based solution processable aqueous suspensions. The flexible solid-state supercapacitors exhibit a maximum capacitance of $568 \mathrm{~F} \mathrm{~cm}^{-3}$, an ultrahigh energy density of $33.2 \mathrm{mWh} \mathrm{cm}^{-3}$ and a power density of $19470 \mathrm{~mW} \mathrm{~cm}{ }^{-3}$. We attribute the excellent electrochemical performance and cycle life to the self-assembled layered architecture with aligned PEDOT nanofiber network confined between the highly conducting $\mathrm{Mo}_{1.33} \mathrm{C}$ layers, which leads to fast reversible redox reactions and improved ion transport through short diffusion paths. The results of XRD and TEM indicates that the higher volumetric capacitances $\left(1310 \mathrm{~F} \mathrm{~cm}^{-3}\right)$ and excellent rate performances compared to pure $\mathrm{Mo}_{1.33} \mathrm{C}$ and untreated $\mathrm{Mo}_{1.33} \mathrm{C} / \mathrm{PEDOT}$ :PSS composite films is facilitated by the formation of PEDOT nanofibers in the sandwich-like Mo1.33C/PEDOT:PSS composite film after treatment with concentrated $\mathrm{H}_{2} \mathrm{SO}_{4}$. Furthermore, the enhanced capacitance is likely due to the synergistic effect of increased interlayer spacing between the $\mathrm{Mo}_{1.33} \mathrm{C}$ layers and the surface redox processes of both the PEDOT and MXene. Our demonstrated results provide a 


\section{WILEY-VCH}

new strategy for designing and fabricating solution-processed conducting polymer/MXene composites for energy-related applications and beyond.

\section{Experimental Section}

Synthesis of the $\mathrm{Mo}_{1.33} \mathrm{C}$ MXene was described previously. ${ }^{[10]}$ Briefly, $1 \mathrm{~g}$ of $\left(\mathrm{Mo}_{2 / 3} \mathrm{Sc}_{1 / 3}\right)_{2} \mathrm{AlC}$ is added to $20 \mathrm{ml} 48 \% \mathrm{HF}$, stirring for $24 \mathrm{~h}$ at RT. After removing the acid, multilayer MXene is delaminated into single/few layer MXene by intercalating with TBAOH. The $\mathrm{Mo}_{1.33} \mathrm{C} / \mathrm{PEDOT}$ :PSS composites is prepared by dropwise addition of a PEDOT:PSS (Clevios $\mathrm{PH}$ 1000) into the colloidal solution of $\mathrm{Mo}_{1.33} \mathrm{C}$. The mixture is stirred for $5 \mathrm{~min}$ and then vacuum-filtered onto nanoporous polypropylene membranes (Celgard 3501, $0.064 \mu \mathrm{m}$ pore size, Celgard LLC) in air. The $\mathrm{H}_{2} \mathrm{SO}_{4}$ treatment is performed by soaking the $\mathrm{Mo}_{1.33} \mathrm{C} / \mathrm{PEDOT}$ :PSS composite film into the concentrated $\mathrm{H}_{2} \mathrm{SO}_{4}$ solution for $24 \mathrm{~h}$ at room temperature. Then the treated film is rinsed with deionized water three times. Finally, the composites film is dried at $110^{\circ} \mathrm{C}$ for about $3 \mathrm{~min}$.

In the three-electrode configuration, the $\mathrm{Mo}_{1.33} \mathrm{C}$ or the composite film is used as working electrodes, platinum foils as counter electrodes and $\mathrm{Ag} / \mathrm{AgCl}$ in $1 \mathrm{M} \mathrm{KCl}$ as the reference electrode using the aqueous solution containing $\mathrm{H}_{2} \mathrm{SO}_{4}(1 \mathrm{M})$ as the electrolyte. The all solidstate supercapacitors is fabricated using Au-coated polyethylene terephthalate (PET) substrate as the flexible conductive substrate and PVA/ $\mathrm{H}_{2} \mathrm{SO}_{4}$ gel electrolyte as the solid electrolyte ( $45 \mu \mathrm{m})$. First, $1 \mathrm{~g}$ of $\mathrm{H}_{2} \mathrm{SO}_{4}$ is mixed with $10 \mathrm{ml}$ deionized water, and then $1 \mathrm{~g}$ of polyvinyl alcohol power is added. The mixture is stirred under $85{ }^{\circ} \mathrm{C}$ until the mixture becomes clear. When the electrolyte is cooled down, it is cast onto the electrodes $(\sim 2 \mu \mathrm{m})$, then left in the fume hood at room temperature for $1 \mathrm{~h}$ to vaporize the excess water. Then the two pieces of electrodes are pressed together. The electrolyte was solidified and functioned as a glue holding all the device components together, and improving the mechanical stability. 


\section{WILEY-VCH}

The electrochemical tests are performed using a VSP potentiostat (BioLogic, France). The impedance measurements are performed with a $5 \mathrm{mV}$ amplitude in a frequency range from 10 $\mathrm{mHz}$ to $100 \mathrm{kHz}$. The characterizations of the film morphology are carried out using SEM (LEO 1550 Gemini) and TEM (LEO 912 OMEGA). XRD is carried out on a PANalytical X'Pert diffractometer using $\mathrm{Cu} \mathrm{K \alpha}$ radiation (45 KV and $40 \mathrm{~mA}$ ). A Hysitron TI950 triboindentor device equipped with a Berkovich indenter is used to measure mechanical properties of the specimens. An array of $4 \times 4$ indentations with a trapezoid loading profile is performed at $50 \mu \mathrm{N}$ peak load for each specimen. A standard fused silica is used for calibration before each measurement.

\section{Supporting Information}

Supporting Information is available from the Wiley Online Library or from the author.

\section{Acknowledgements}

This work was financed by Swedish Energy Agency [EM 42033-1], the SSF Synergy Grant FUNCASE, the SSF Research Infrastructure Fellow program no. RIF 14-0074 and RIF140079, and by the Knut and Alice Wallenberg (KAW) Foundation through a Fellowship Grant, a Project Grant (KAW 2015.0043), and for support of the electron microscopy laboratory in Linköping. The Swedish Research Council (VR) is also acknowledged through project grant 642-2013-8020.

Received: ((will be filled in by the editorial staff))

Revised: ((will be filled in by the editorial staff)) Published online: ((will be filled in by the editorial staff))

\section{References}

[1] a) Y. Gogotsi, P. Simon, science 2011, 334, 917; b) Y. Xu, Y. Tao, X. Zheng, H. Ma, J. Luo, F. Kang, Q-H. Yang, Adv. Mater. 2015, 27, 8082; c) K. Qin, J. Kang, J. Li, C. Shi, Y. Li, Z. Qiao, N. Zhao, ACS Nano. 2015, 9, 481. 


\section{WILEY-VCH}

[2] a) Z. Cao, B. Wei, Energy Environ. Sci. 2013, 6, 3183; b) M.-Q. Zhao, Q. Zhang, J.-Q. Huang, G.-L. Tian, T.-C. Chen, W.-Z. Qian, F. Wei, Carbon, 2013, 54, 403; c) H. Niu, D. Zhou, X. Yang, X. Li, Q. Wang, F. Qu, J. Mater. Chem. A 2015, 3, 18413.

[3] P. Simon, Y. Gogotsi, Nat. Mater. 2008, 7, 845.

[4] Y. Wang, Y. Song, Y. Xia, Chem. Soc. Rev. 2016, 45, 5925.

[5] a) V. Nicolosi, M. Chhowalla, M. G. Kanatzidis, M. S. Strano, J. N. Coleman, Science 2013, 340, 1226419; b) G. Fiori, F. Bonaccorso, G. Iannaccone, T. Palacios, D. Neumaier, A. Seabaugh, S. K. Banerjee, L. Colombo, Nat. Nanotechnol. 2014, 9, 768. c) F. Xia, H. Wang, D. Xiao, M. Dubey, A. Ramasubramaniam, Nat. Photonics 2014, 8, 899; d) F. H. L. Koppens, T. Mueller, P. Avouris, A. C. Ferrari, M. S. Vitiello, M. Polini, Nat. Nanotechnol, 2014, 9, 780; e) D. Akinwande, N. Petrone, J. Hone, Nat. Commun. 2014, 5, 5678; f) A. Cepellotti, G. Fugallo, L. Paulatto, M. Lazzeri, F. Mauri, N, Marzari, Nat. Commun. 2015, 6, 6400.

[6] a) M. Naguib, O. Mashtalir, J. Carle, V. Presser, J. Lu, L. Hultman, Y. Gogotsi, M. W. Barsoum, ACS Nano 2012, 6, 1322; b) M. Naguib, M. Kurtoglu, V. Presser, J. Lu, J. Niu, M. Heon, L. Hultman, Y. Gogotsi, M. W. Barsoum, Adv. Mater. 2011, 23, 4248; c) M. Naguib, J. Halim, J. Lu, K. M. Cook, L. Hultman, Y. Gogotsi, M. W. Barsoum, J. Am. Chem. Soc. 2013, 135, 15966.

[7] J. Halim, S. Kota, M R. Lukatskaya, M. Naguib, M.-Q. Zhao, E. J. Moon, J. Pitock, J. Nanda, S. J. May, Y. Gogotsi, M. W. Barsoum, Adv. Funct. Mater. 2016, 26, 3118.

[8] X. Liang, A. Garsuch, L. F. Nazar, Angew. Chem. Int. Ed. 2015, 54, 3907.

[9] a) X. Wang, S. Kajiyama, H. Iinuma, E. Hosono, S. Oro, I. Moriguchi, M. Okubo, A. Yamada, Nat. Commun. 2015, 6, 6544; b) Y. Dall’Agnese, P.-L. Taberna, Y. Gogotsi, P. Simon, J. Phys. Chem. Lett. 2015, 2, 2305. 


\section{WILEY-VCH}

[10] M. Ghidiu, M. R. Lukatskaya, M.-Q. Zhao, Y. Gogotsi, M. W. Barsoum, Nature 2014, 516, 78.

[11] Q. Tao, M. Dahlqvist, J. Lu, S. Kota, R. Meshkian, J. Halim, J. Palisaitis, L. Hultman, M. W. Barsoum, P. O. Å. Persson, J. Rosen, Nat. Commun. 2017, 8, 14949.

[12] a) M.-Q. Zhao, C. E. Ren, Z. Ling, M. R. Lukatskaya, C. Zhang, K. L. V. Aken, M. W. Barsoum, Y. Gogotsi, Adv. Mater. 2015, 27, 339; b) Z. Ling, C. E. Ren, M. Zhao, J. Yang, J. M. Giammarco, J. Qiu, M. W. Barsoum, Y. Gogotsi, Proc. Natl. Acad. Sci. USA 2014, 111, 16676.

[13] a) M. R. Lukatskaya, S. Kota, Z. Lin, M.-Q Zhao, N. Shpigel, M. D. Levi, J. Halim, P.-L. Taberna, M. W. Barsoum, P. Simon, Y. Gogotsi, Nature Energy. 2017, 2, 17105.

[14] a) N. Kim, S. Kee, S. H. Lee, B. H. Lee, Y. H. Kahng, Y.-R. Jo, B.-J. Kim, K. Lee, Adv. Mater. 2014, 26, 2268.

[15] a) M. Boota, B. Anasori, C. Voigt, M.-Q. Zhao, M. W. Barsoum, Y. Gogotsi, Adv. Mater. 2016, 28, 1517; b) M. Zhu, Y. Huang, Q. Deng, J. Zhou, Z. Pei, Q. Xue, Y. Huang, Z. Wang, H. Li, Q. Huang, C. Zhi, Adv. Energy Mater. 2016, 6, 1600969; c) C. Chi, M. Boota, X. Xie, M. Zhao, B. Anasori, C. E. Ren, L. Miao, J. Jiang, Y. Gogotsi, J. Mater. Chem. A 2017, 5, 5260. [16] a) H. Shi, C. Liu, Q. Jiang, J. Xu, Adv. Electron. Mater. 2015, 1, 1500017; b) M. Zhang, Q. Zhou, J. Chen, X. Yu, L. Huang, Y. Li, C. Li, G. Shi, Energy Environ. Sci. 2016, 9, 2005, c) Y. Xia, K. Sun, J. Ouyang, Adv. Mater. 2012, 24, 2436.

[17] M. Naguib, R. R. Unocic, B. L. Armstrong, J. Nanda, Dalton Trans. 2015, 44, 9353.

[18] M. Ghidiu, J. Halim, S. Kota, D. Bish, Y. Gogotsi, M. W. Barsoum, Chem. Mater. 2016, 28, 3507.

[19] Q. Gao, J. Come, M. Naguib, S. Jesse, Y. Gogotsi, N. Balke, Faraday Discuss. 2017, DOI: 10.1039/C6FD00251J. 


\section{WILEY-VCH}

[20] M. Park, H. J. Kim, I. Jeong, J. Lee, H. Lee, H. J. Son, D.-E. Kim, M. J. Ko, Adv. Energy Mater. 2015, 5, 1501406.

[21] a) J. M. D’Arcy, M. F. El-Kady, P. P. Khine, L. Zhang, S. H. Lee, N. R. Davis, D. S. Liu, M. T. Yeung, S. Y. Kim, C. L. Turner, A. T. Lech, P. T. Hammond, R. B. Kaner, ACS nano, 2014, 8, 1500; b) Z. Li, G. Ma, R. Ge, F. Qin, X. Dong, W. Meng, T. Liu, J. Tong, F. Jiang, Y. Zhou, K. Li, X. Min, K. Huo, Y. Zhou, Angew. Chem. Int. Ed. 2016, 55, 979; c) Z.-S. Wu, Z. Liu, K. Parvez, X. Feng, K. Müllen, Adv. Mater. 2015, 27, 3669; d) Y.-Y. Peng, B. Akuzum, N. Kurra, M.-Q. Zhao, M. Alhabeb, B. Anasori, E. C. Kumbur, H. N. Alshareef, M.-D. Gerc, Y. Gogotsi, Energy Environ. Sci. 2016, 9, 2847; e) H. Li, Y. Hou, F. Wang, M. R. Lohe, X. Zhuang, L. Niu, X. Feng, Adv. Energy Mater. 2017, 7, 1601847; f) N. Kurra, J. Park, H. N. Alshareef, J. Mater. Chem. A 2014, 2, 17058.
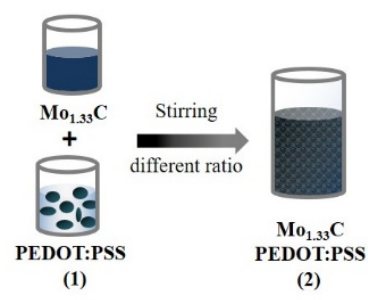

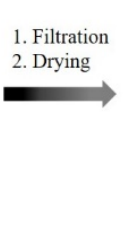

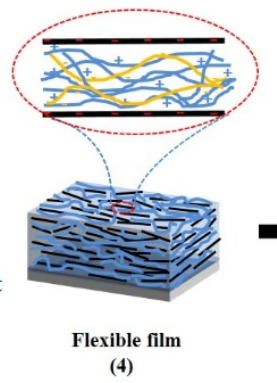

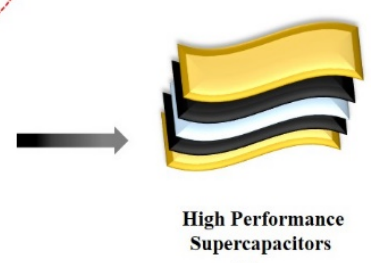

(5)

Figure 1. Schematic illustration of the preparation of composite films and the fabrication of a solid-state supercapacitor. 
WILEY-VCH
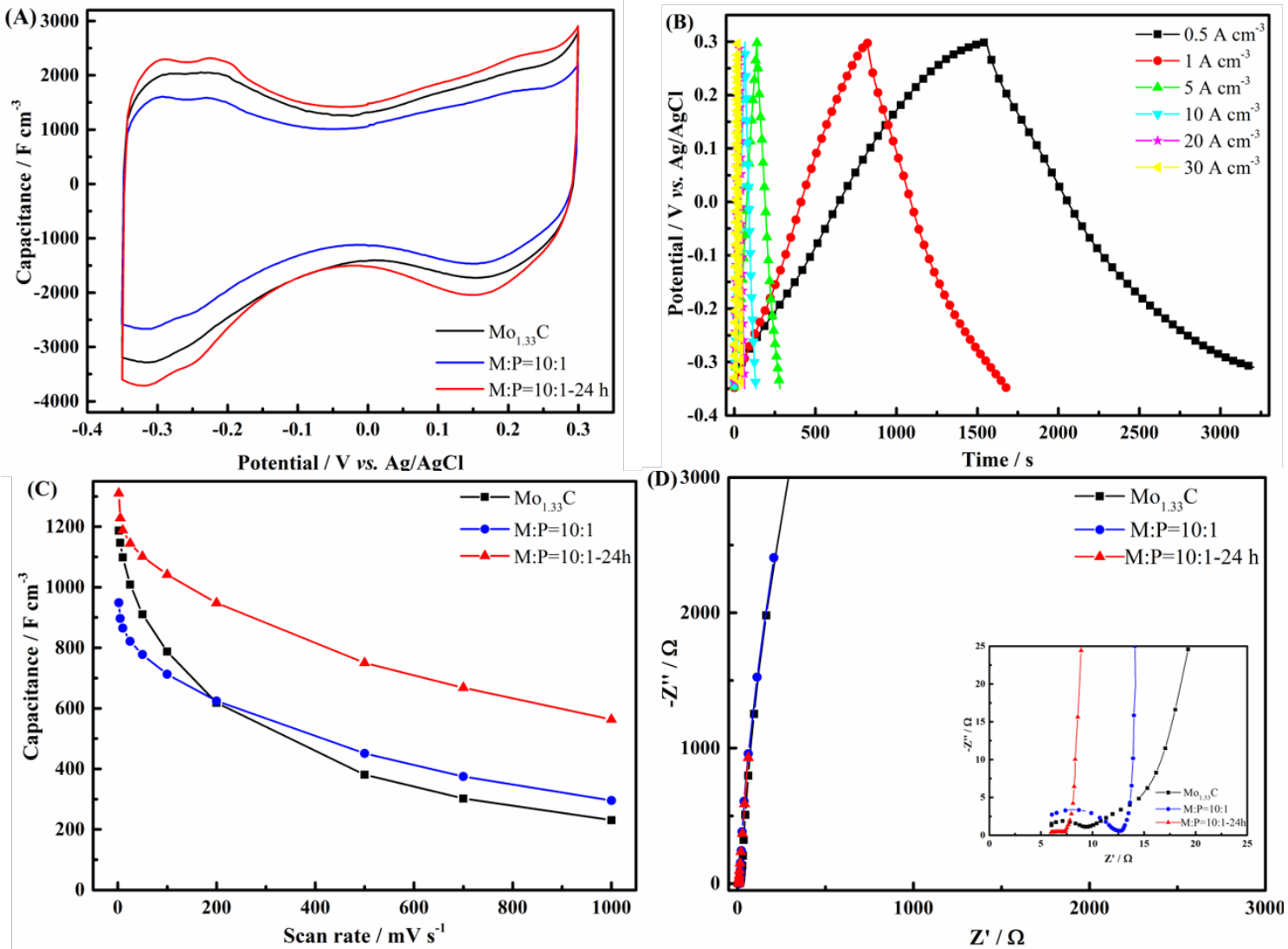

Figure 2. (A) Volumetric capacitance of pristine $\mathrm{Mo}_{1.33} \mathrm{C}$ and composite films (M:P=10:1) at scan rate $2 \mathrm{mV} / \mathrm{s}$. (B) Galvanostatic charge/discharge curves of $\mathrm{M}: \mathrm{P}=10: 1-24 \mathrm{~h}$ at different current densities. (C) Gravimetric rate performances of pristine $\mathrm{Mo}_{1.33} \mathrm{C}$ and composite films. (D) electrochemical impedance spectroscopy of pristine $\mathrm{Mo}_{1.33} \mathrm{C}$ and composite films. 


\section{WILEY-VCH}

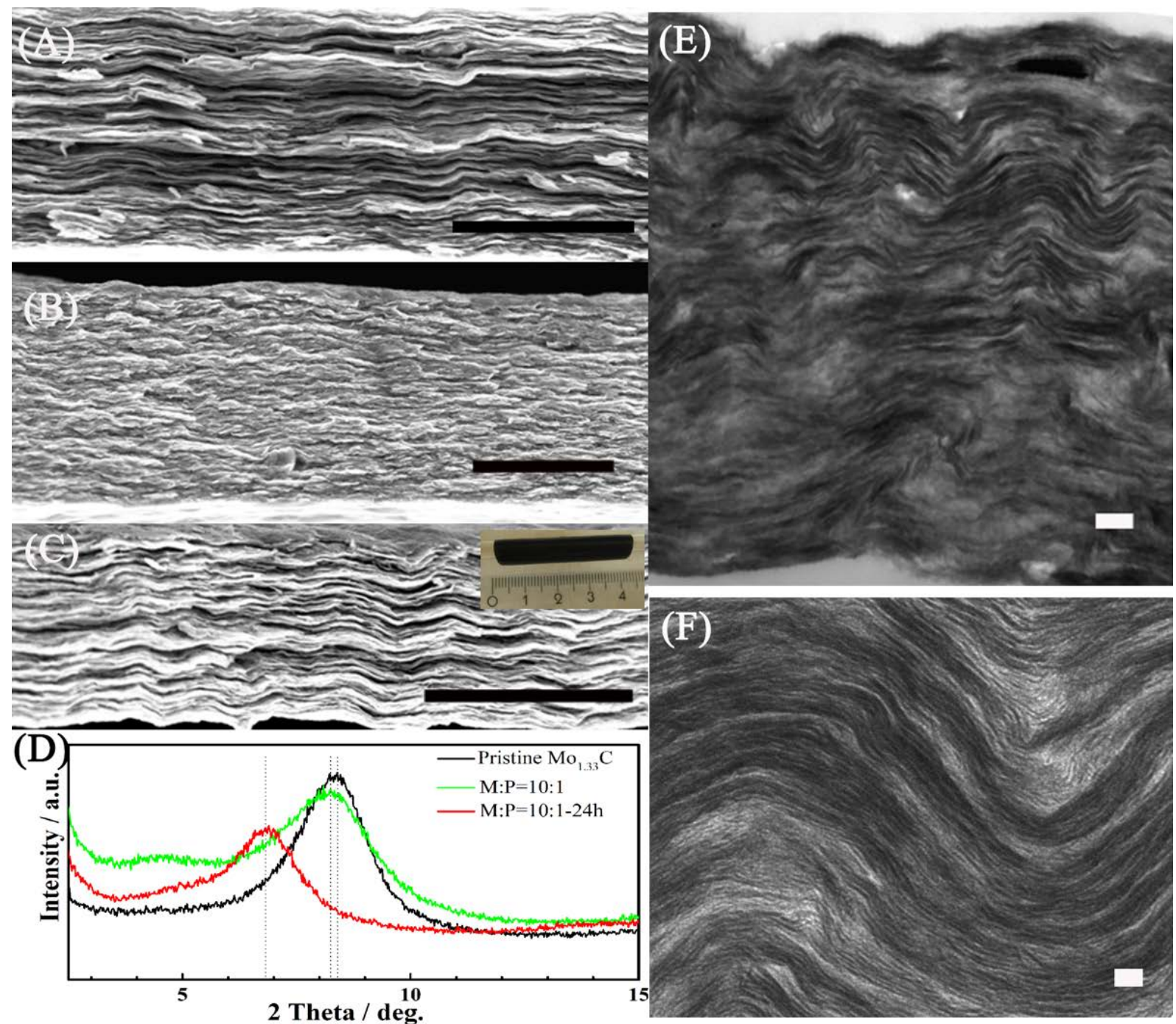

Figure 3. Cross-sectional SEM image of (A) pristine $\mathrm{Mo}_{1.33} \mathrm{C}$, (B) $\mathrm{M}: \mathrm{P}=10: 1$ and (C) $\mathrm{M}: \mathrm{P}=10: 1-24 \mathrm{~h}$. Scale bars: $2 \mu \mathrm{m}$. (D) XRD pattern of the PEDOT:PSS intercalated MXene compared with delaminated MXene film. (E) Low-magnification (scale bar: $200 \mathrm{~nm}$ ) and (F) high-magnification (scale bar: $40 \mathrm{~nm}$ ) cross-sectional TEM images of $\mathrm{M}: \mathrm{P}=10: 1-24 \mathrm{~h}$ with aligned PEDOT:PSS chains between MXene sheets. Inset of (C): Digital photographs showing a flexible and free-standing sandwich-like MXene/PEDOT:PSS paper wrapping of around a 5mm-diameter glass rod. 


\section{WILEY-VCH}
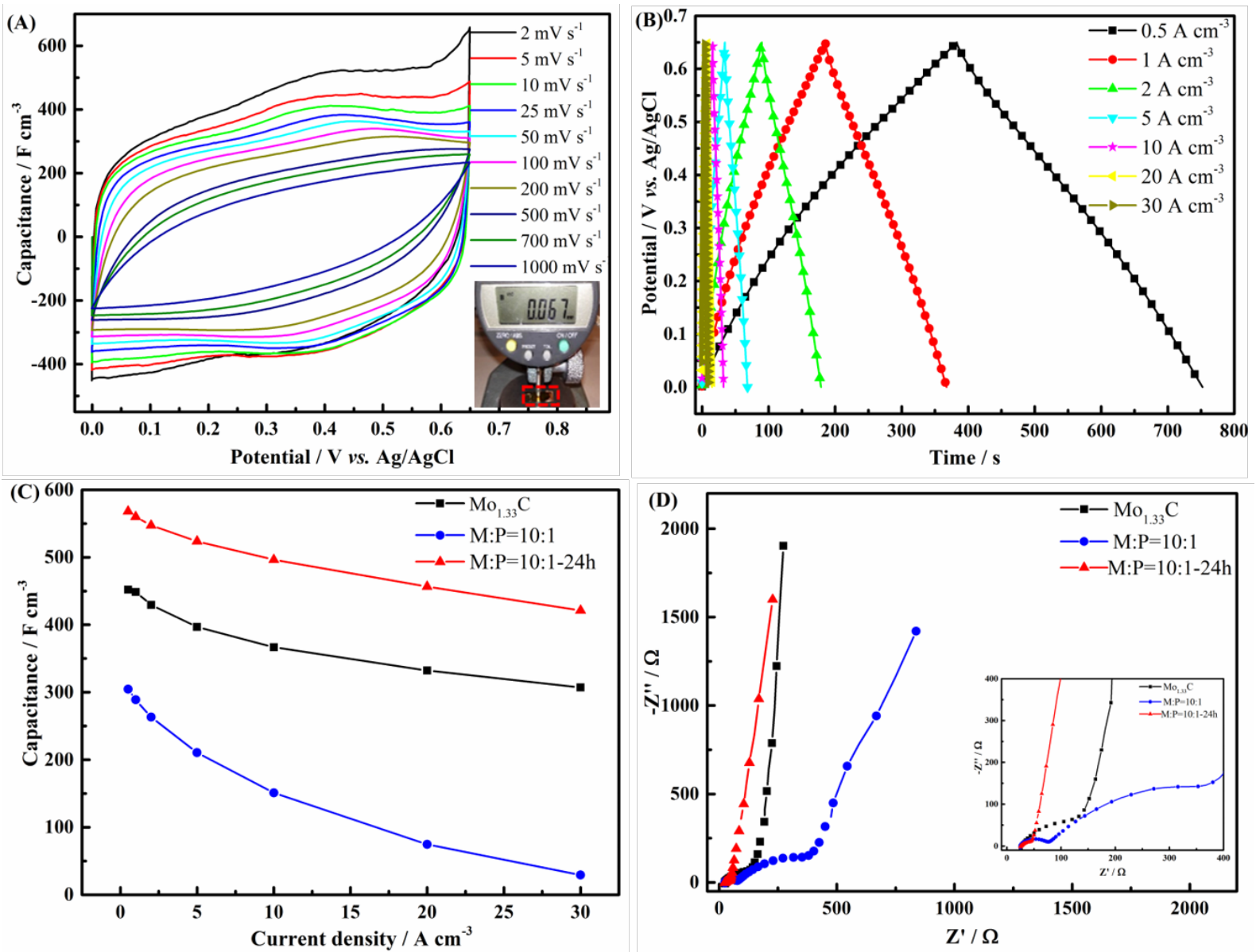

Figure 4. (A) Typical cyclic voltammograms (inset: thickness of the as-prepared flexible solidstate supercapacitor) and (B) galvanostatic charge/discharge curves of the flexible solid-state device. (C) The comparison of volumetric capacitances of $\mathrm{Mo}_{1.33} \mathrm{C}, \mathrm{M}: \mathrm{P}=10: 1$ and $\mathrm{M}: \mathrm{P}=10: 1-$ 24h at different current density. (D) Nyquist plot of the device tested at the open-circuit potential within the frequency range from $10^{-2}$ to $10^{5} \mathrm{~Hz}$. The inset shows the enlarged plot in the high frequency region.
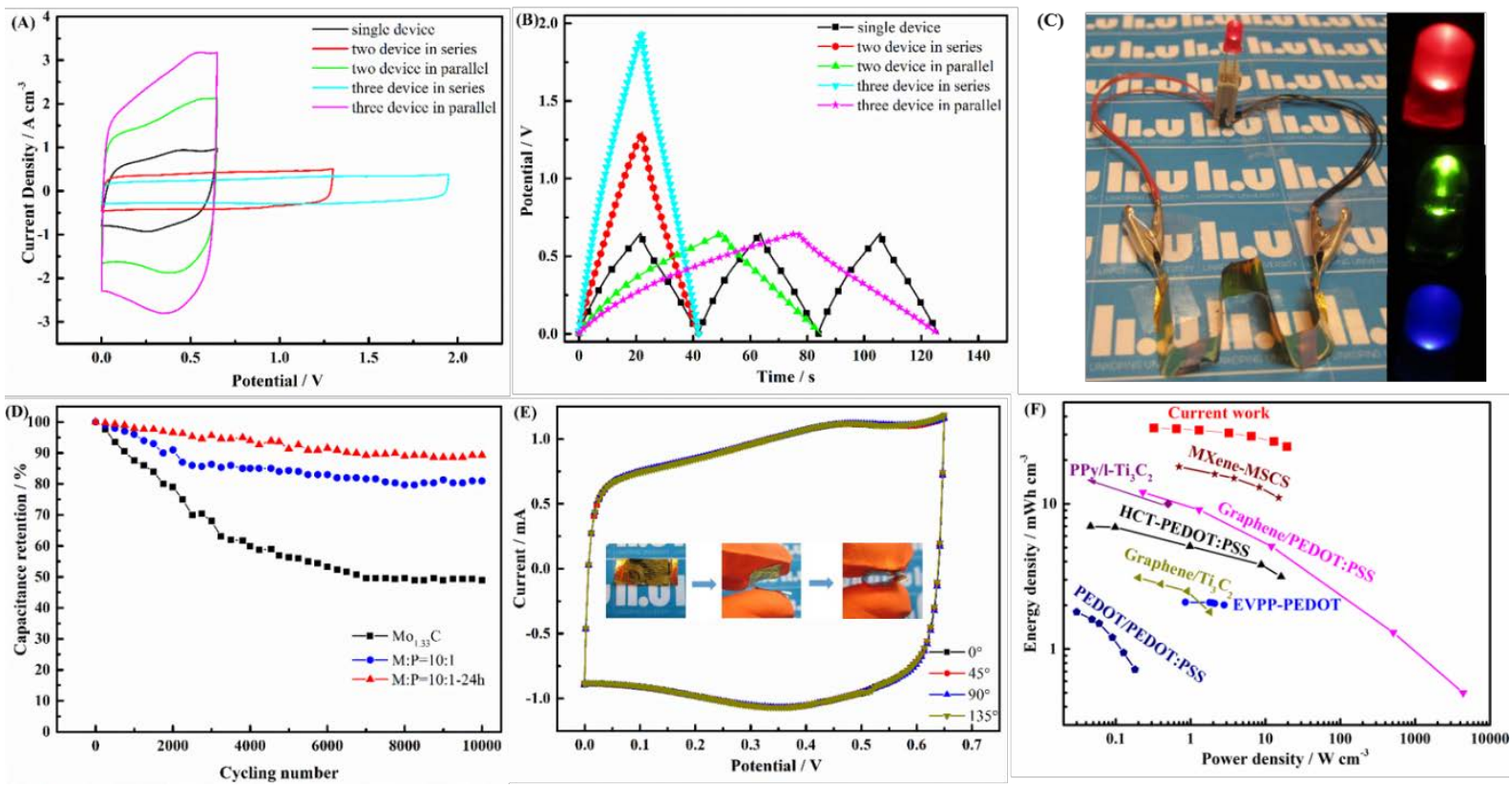
Figure 5. (A) CV curves of devices (M:P=10:1-24h) connected in series and in parallel at a scan rate of $100 \mathrm{mV} \mathrm{s}^{-1}$. A single device is shown for comparison. (B) GCD curves of devices $\left(\mathrm{M}: \mathrm{P}=10: 1-24 \mathrm{~h}\right.$ ) connected in series and in parallel at a current density of $1 \mathrm{~A} \mathrm{~cm}^{-3}$. (C) Opitical image of a light-emitting diode (LED) powered by four tandem devices. (D) Cyclic stability of $\mathrm{Mo}_{1.33} \mathrm{C}, \mathrm{M}: \mathrm{P}=10: 1$ and $\mathrm{M}: \mathrm{P}=10: 1-24 \mathrm{~h}$ devices. (E) $\mathrm{CV}$ curves of the $\mathrm{M}: \mathrm{P}=10: 1-24 \mathrm{~h}$ device bended with different angles at $100 \mathrm{mV} \mathrm{s}^{-1}$. Inset: Optical image of the flexible ultra-thin supercapacitor. (F) Energy and power density of the $\mathrm{M}: \mathrm{P}=10: 1-24 \mathrm{~h}$ device compared with previously reported devices.

Table 1. The capacitance performance of the composite film for different MXene:polymer mass ratio

\begin{tabular}{ccccc}
\hline \multirow{2}{*}{$\begin{array}{c}\mathrm{M}: \mathrm{P}^{\mathrm{a})} \\
(\mathrm{w} / \mathrm{w})\end{array}$} & $\begin{array}{c}2 \mathrm{mV} / \mathrm{s} \\
{\left[\mathrm{F} \mathrm{cm}^{-3}\right]}\end{array}$ & $\begin{array}{c}5 \mathrm{mV} / \mathrm{s} \\
{\left[\mathrm{F} \mathrm{cm}^{-3}\right]}\end{array}$ & $\begin{array}{c}24 \mathrm{mV} / \mathrm{s} \\
{\left[\mathrm{F} \mathrm{cm}^{-3}\right]}\end{array}$ & $\begin{array}{c}5 \mathrm{mV} / \mathrm{s} \\
{\left[\mathrm{F} \mathrm{cm}^{-3}\right]}\end{array}$ \\
\hline Pristine M & $\mathbf{1 1 8 7}$ & $\mathbf{1 1 1 2}$ & 1023 & 926 \\
$50: 1$ & 939 & 866 & 983 & 938 \\
$20: 1$ & 1095 & 996 & 1238 & 1172 \\
$\mathbf{1 0 : 1}$ & $\mathbf{9 4 9}$ & $\mathbf{8 9 6}$ & $\mathbf{1 3 1 0}$ & $\mathbf{1 2 6 6}$ \\
$5: 1$ & 690 & 662 & 808 & 756 \\
$2: 1$ & 587 & 528 & 662 & 633 \\
$1: 1$ & 419 & 377 & 544 & 514 \\
$1: 2$ & 255 & 223 & 462 & 434 \\
$1: 5$ & 143 & 128 & 392 & 372 \\
$\mathrm{P}$ & 31 & 20 & 94 & 81 \\
\hline
\end{tabular}

${ }^{\text {a) }} \mathrm{M}=\mathrm{Mo}_{1.33} \mathrm{C}, \mathrm{P}=\mathrm{PEDOT}$ :PSS; ${ }^{\text {b) }}$ The film did not undergo any treatment; ${ }^{\mathrm{c})}$ The film was treated with concentrated $\mathrm{H}_{2} \mathrm{SO}_{4}$ for 24 hours. 


\section{WILEY-VCH}

\section{The table of contents}

A MXene-based solution processable flexible solid-state supercapacitor with high performance is developed from a MXene/PEDOT:PSS composite film. After post-treatment with concentrated $\mathrm{H}_{2} \mathrm{SO}_{4}$, the PEDOT nanofiber network is aligned between the MXene sheets, leading to highly improved flexibility and, most importantly, improved capacitances (1310 F $\mathrm{cm}^{-3}$ ), rate-capabilities and stability.

Keyword

solid-state supercapacitor, MXene, Mo ${ }_{1.33} \mathrm{C}$, PEDOT:PSS, composite film

Leiqiang Qin, Quanzheng Tao, Ahmed El Ghazaly, Julia Fernández-Rodríguez, Per O. Å. Persson, Johanna Rosen* and Fengling Zhang*

High Performance Ultrathin Flexible Solid-State Supercapacitors based on Solution Processable Mo1.33C MXene and PEDOT:PSS

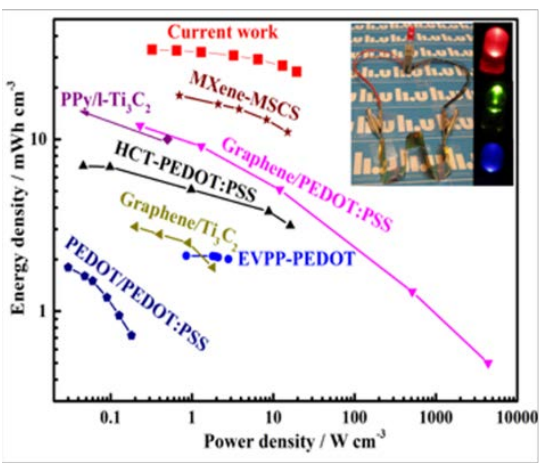




\section{WILEY-VCH}

Copyright WILEY-VCH Verlag GmbH \& Co. KGaA, 69469 Weinheim, Germany, 2016.

\section{Supporting Information}

High Performance Ultrathin Flexible Solid-State Supercapacitors based on Solution Processable Mo1.33C MXene and PEDOT:PSS

Leiqiang Qin ${ }^{\dagger}$, Quanzheng Tao ${ }^{\dagger}$, Ahmed El Ghazaly, Julia Fernández-Rodríguez, Per O. A. Persson, Johanna Rosen* and Fengling Zhang*

Dr. L. Qin, Mr. Q. Tao, Mr. A. El Ghazaly, Prof. P. O. Å. Persson, Prof. J. Rosen, Prof. F. Zhang

Department of Physics, Chemistry and Biology (IFM), Linköping University, SE-581 83 Linköping, Sweden

Prof. J. Fernández-Rodríguez

Centre for Cellular Imaging, Sahlgrenska Academy, University of Gothenburg, SE-405 30, Gothenburg, Sweden

E-mail: johanna.rosen@liu.se; fengling.zhang@liu.se

${ }^{\dagger}$ L. Qin and Q. Tao contributed equally to this work. 


\section{WILEY-VCH}

The volumetric capacitance from the cyclic voltammetry data is determined from the following equation (1):

$$
C=\frac{1}{\Delta V} \int \frac{j d V}{s}
$$

$\mathrm{C}$ is the normalized capacitance (in units of $\mathrm{F} \mathrm{cm}^{-3}$ ), $j$ is the current density (in $\mathrm{A} \mathrm{cm}^{-3}$ ), $\mathrm{s}$ is the rate (in $\mathrm{V} \mathrm{s}^{-1}$ ), $\mathrm{V}$ is the voltage (in $\mathrm{V}$ ), $\Delta \mathrm{V}$ is the voltage window (in $\mathrm{V}$ ). Calculations of the gravimetric capacitance (in $\mathrm{F} \mathrm{g}^{-1}$ ) is performed using current density per electrode weight (in A $\left.g^{-1}\right)$.

The volumetric specific capacitance from galvanostatic charge/discharge data is calculated from the following equation (2):

$$
C=\frac{2 I \mathrm{t}}{\Delta V v}
$$

where I and t represent the discharge current (A) and time (s), respectively; $\Delta \mathrm{V}$ is the voltage during the discharge process after iR drop $(\mathrm{V}), v$ is the volume of one electrode or device.

The volumetric energy density of the device is obtained from the formula given in Equation (3):

$$
E=\frac{1}{2} \times C_{\text {device }}^{\text {volumetric }} \times \frac{(\Delta V)^{2}}{3600}
$$

where $E$ is the energy density (in $\mathrm{Wh} / \mathrm{cm}^{3}$ ), $\mathrm{C}$ device volumetric is the volumetric capacitance obtained from Equation (1) and $\Delta \mathrm{V}$ is the discharge voltage range (in volts, $\mathrm{V}$ ).

The power density of the device is calculated from the formula given in Equation (4):

$$
P=\frac{E}{\Delta t} \times 3600
$$

where $\mathrm{P}$ is the power density (in $\mathrm{W} / \mathrm{cm}^{3}$ ), $\mathrm{E}$ is the volumetric energy density obtained from Equation (3) and $\Delta \mathrm{t}$ is the discharge time (in seconds, s). 


\section{WILEY-VCH}

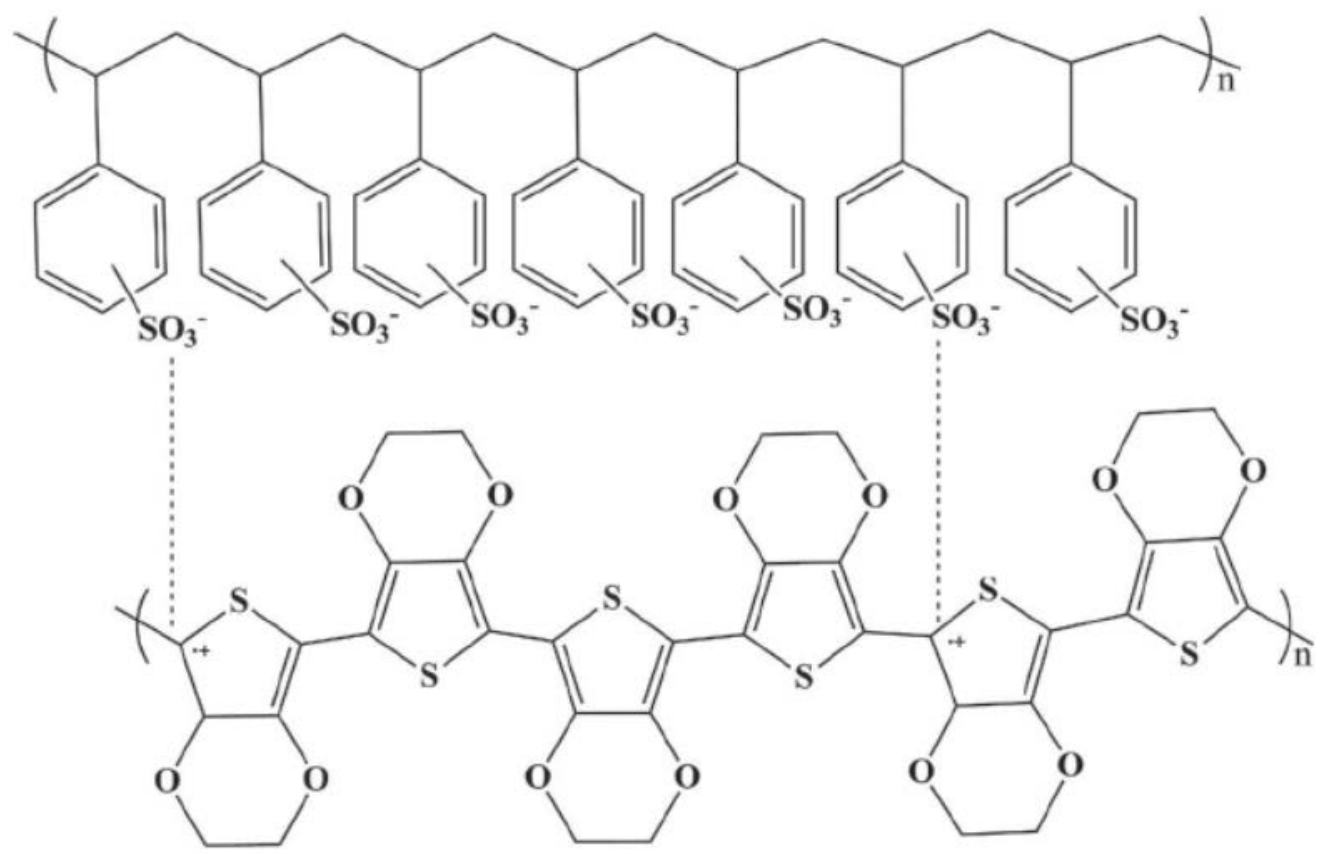

Scheme S1. The chemical structure of PEDOT:PSS. 
WILEY-VCH
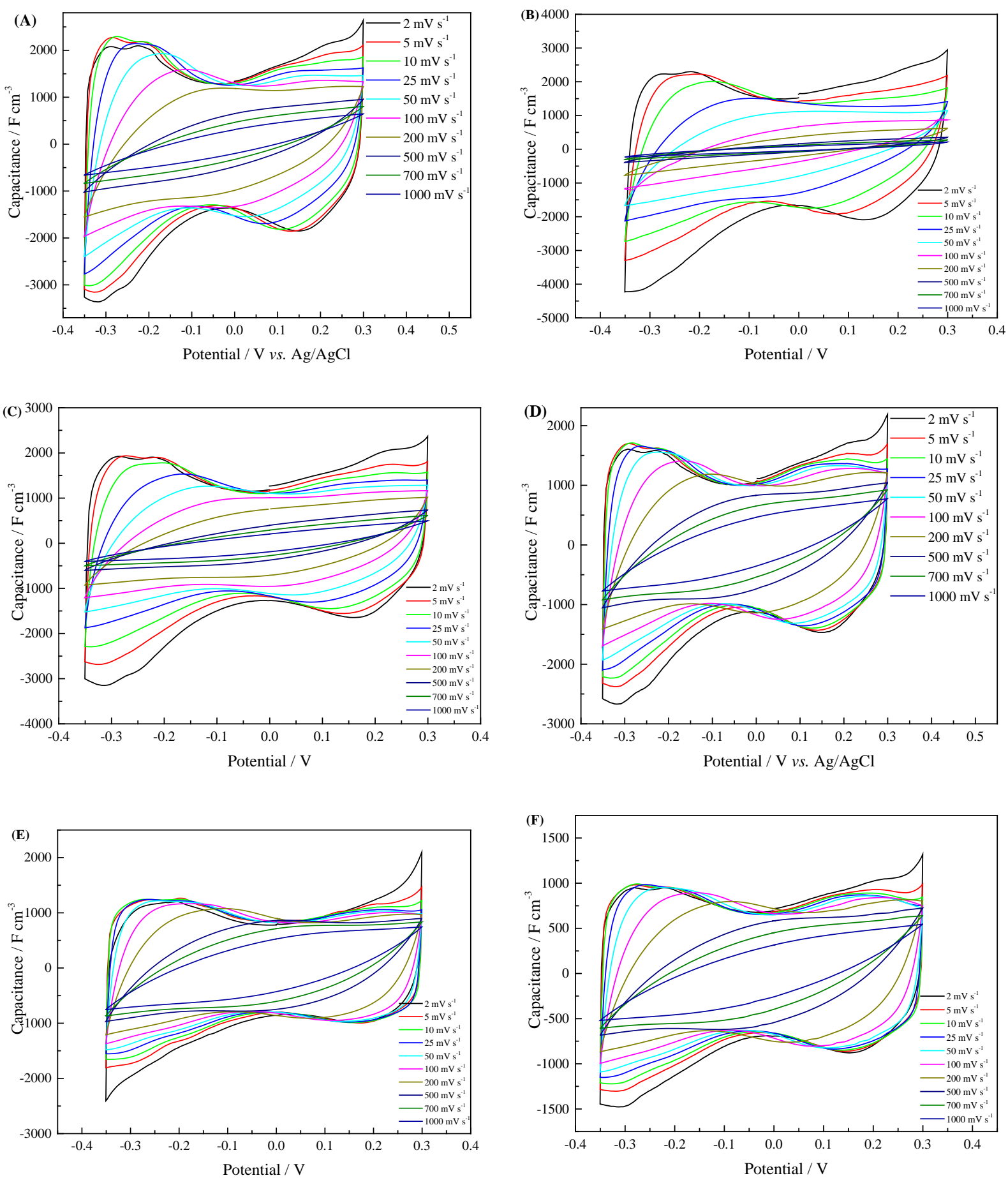
WILEY-VCH
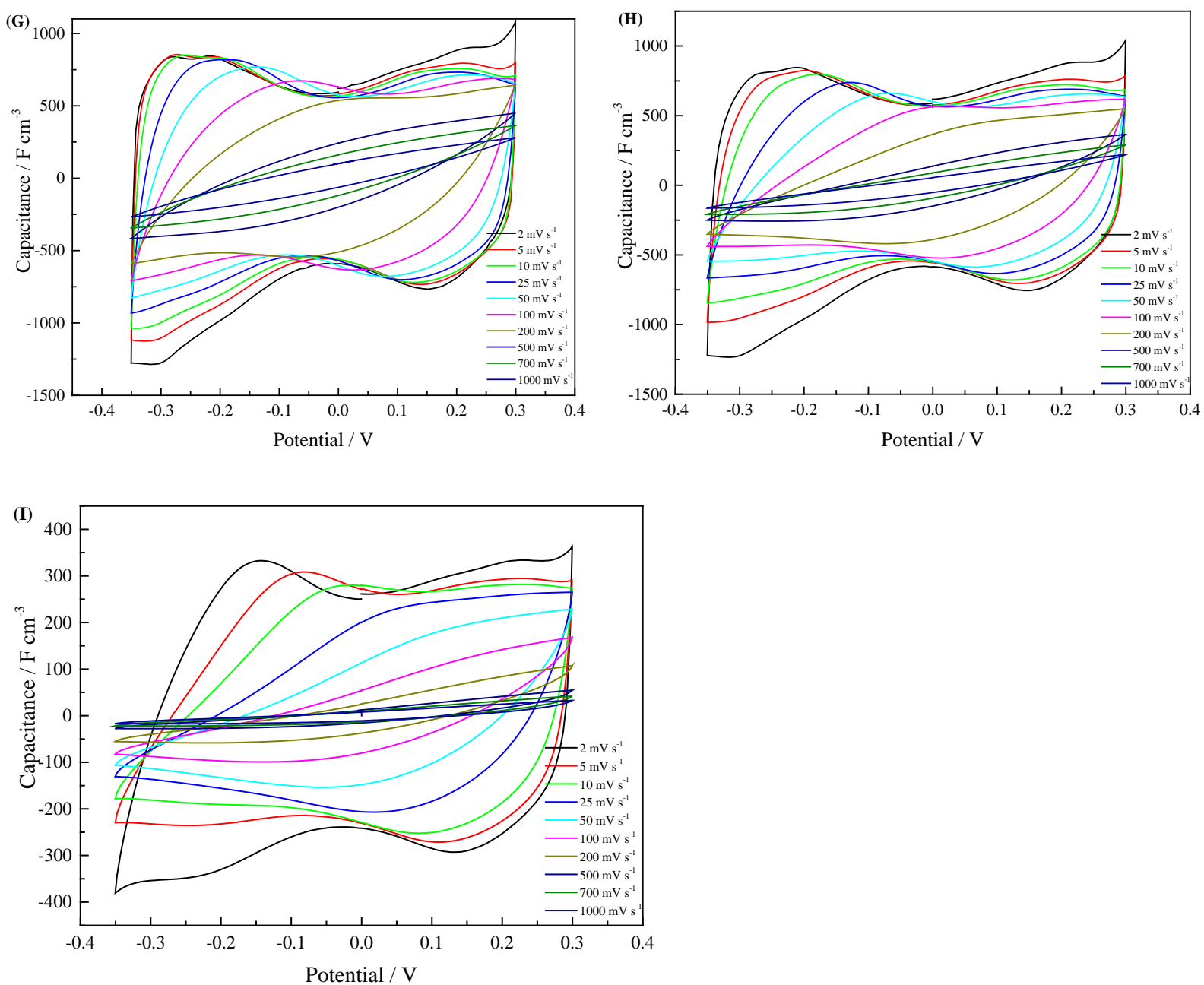

Figure S1. Cyclic voltammetry (CV) profiles of (A) Mxene, (B) M:P=50:1, (C) $M: P=20: 1$, (D) $\mathrm{M}: \mathrm{P}=10: 1$, (E) $\mathrm{M}: \mathrm{P}=5: 1$, (F) $\mathrm{M}: \mathrm{P}=2: 1$, (G) $\mathrm{M}: \mathrm{P}=1: 1$, (H) $\mathrm{M}: \mathrm{P}=1: 2$ and (I) $\mathrm{M}: \mathrm{P}=1: 5$ obtained at different scanning rates. 
WILEY-VCH
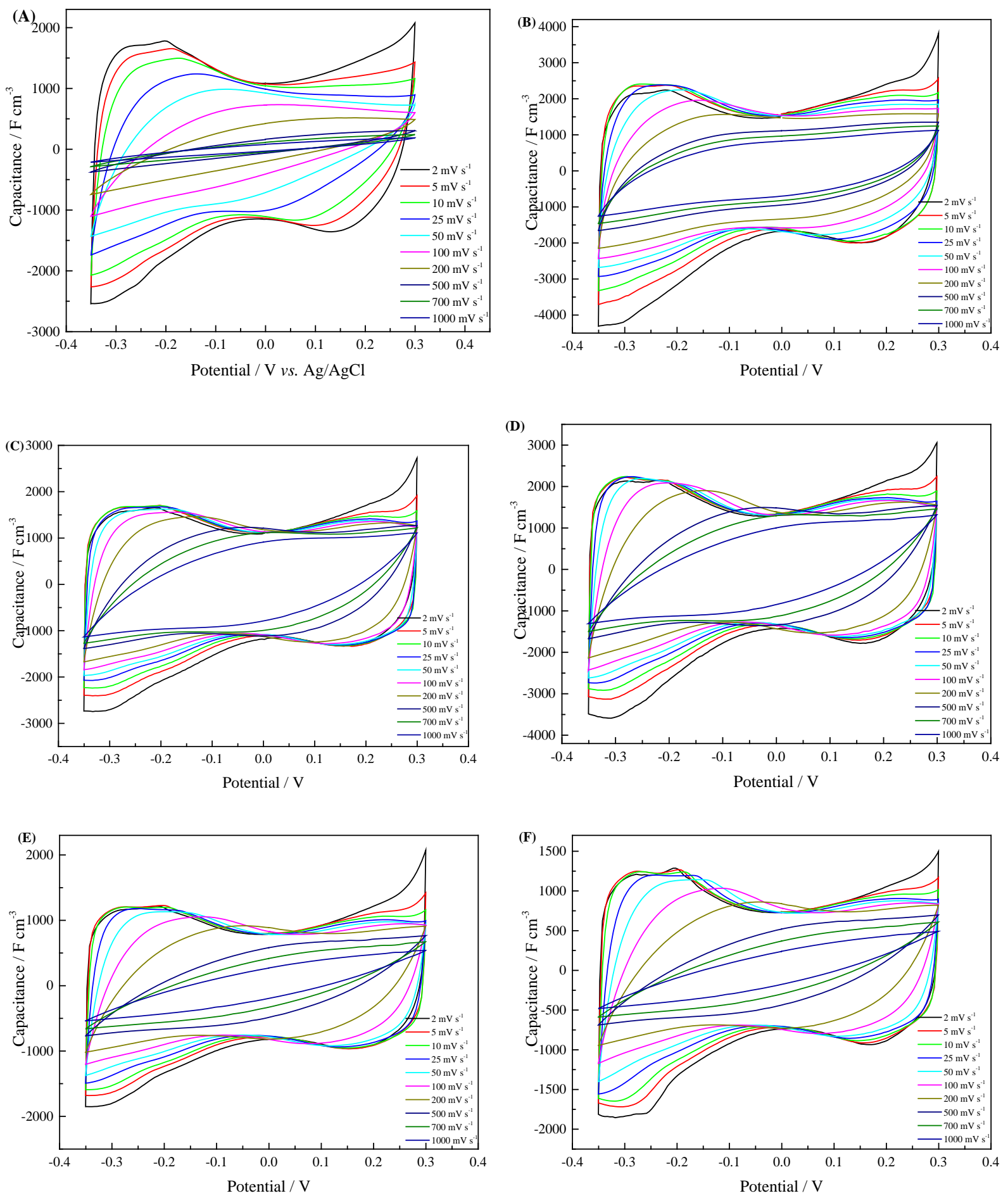
WILEY-VCH
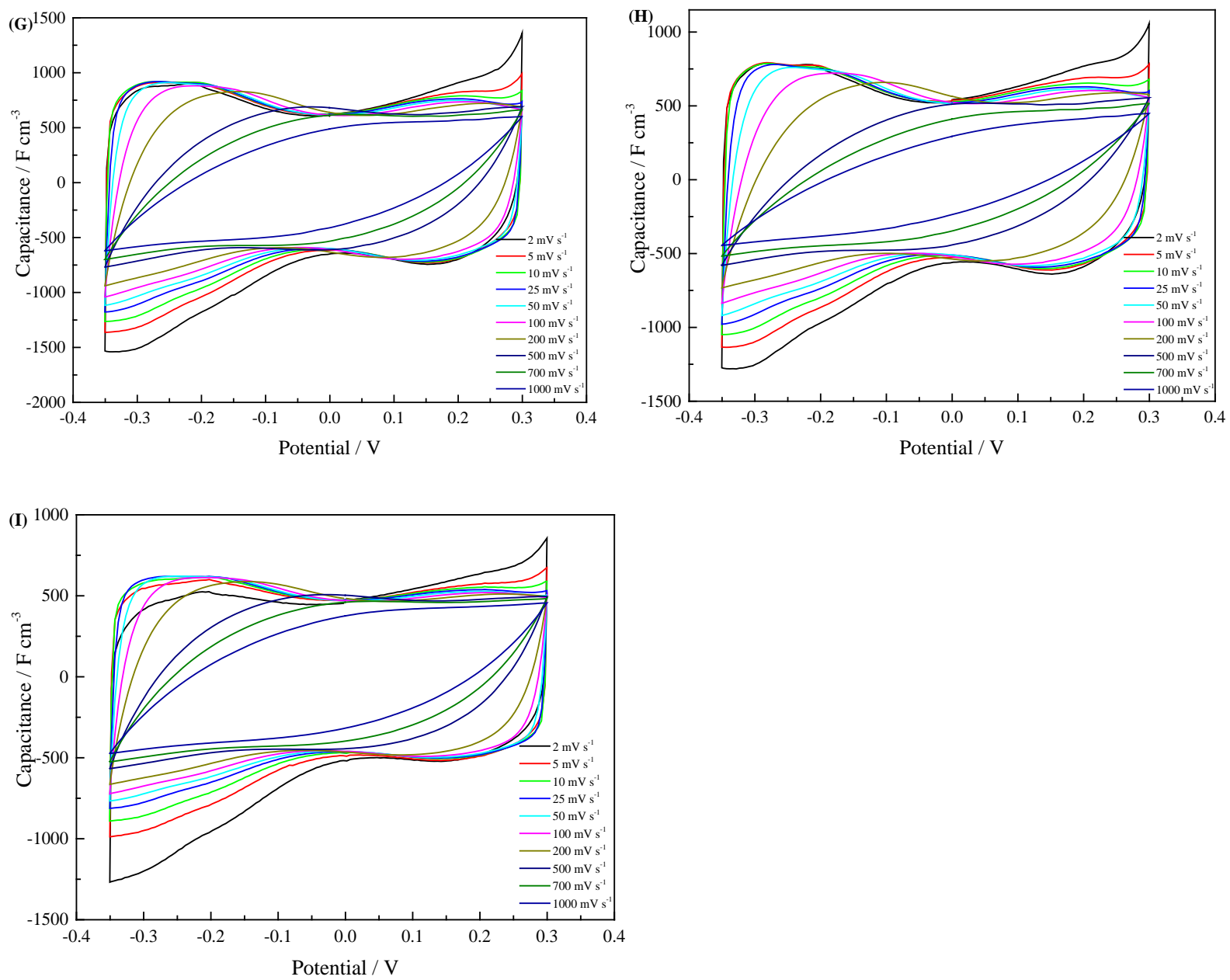

Figure S2. Cyclic voltammetry (CV) profiles of (A) MXene-24h, (B) M:P=50:1-24h, (C) $M: P=20: 1-24 h$, (D) $M: P=10: 1-24 h$, (E) $M: P=5: 1-24 h$, (F) $M: P=2: 1-24 h$, (G) $M: P=1: 1-24 h,(H)$ $\mathrm{M}: \mathrm{P}=1: 2-24 \mathrm{~h}$ and (I) $\mathrm{M}: \mathrm{P}=1: 5-24 \mathrm{~h}$ obtained at different scanning rates.
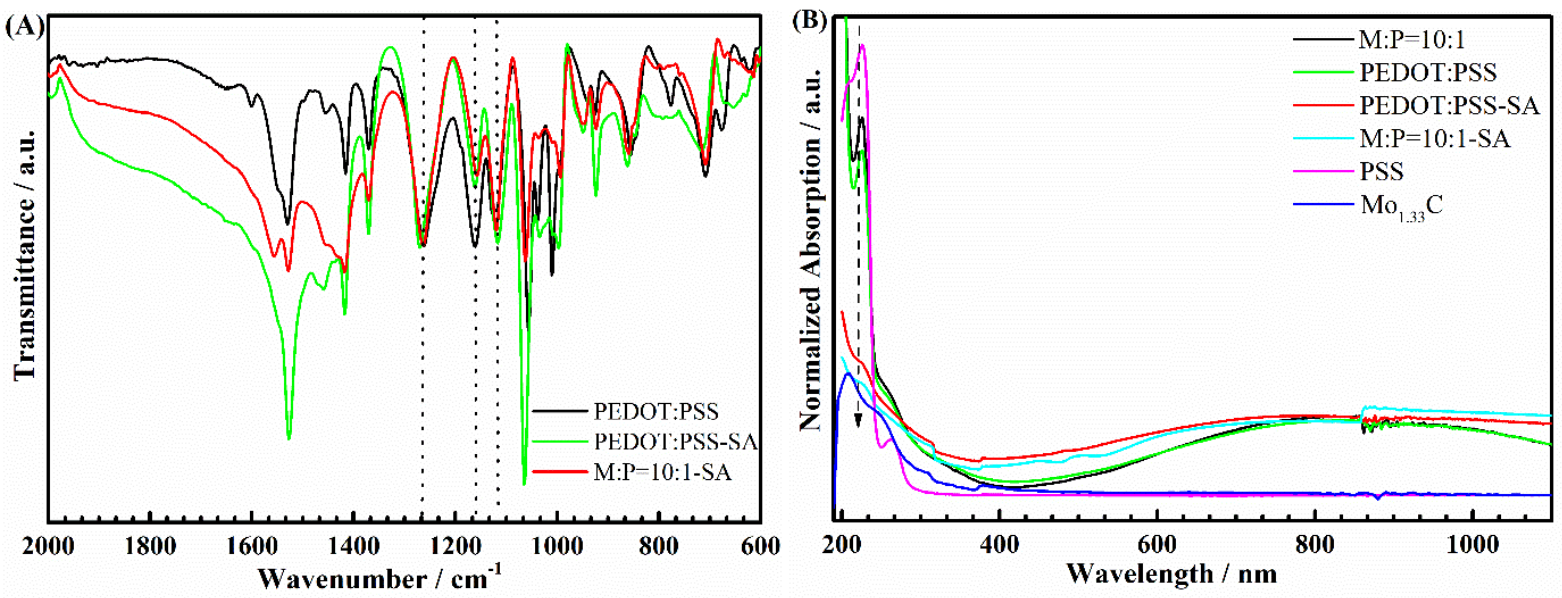

Figure S3. (A) The FT-IR spectra of PEDOT:PSS, PEDOT:PSS-SA and M:P=10:1-SA. (B) Absorption spectra of PSS, PEDOT:PSS, M:P=10:1, PEDOT:PSS-SA and M:P=10:1-SA. 


\section{WILEY-VCH}

FTIR and Absorption spectra were used to estimate the relative PEDOT/PSS ratio in the composite. For the sample preparation, the PEDOT:PSS was spin coated on quartz. The composite film of $\mathrm{M}: \mathrm{P}=10: 1$ was drip casted on the quartz. The samples of PEDOT:PSS and $\mathrm{M}: \mathrm{P}=10: 1$ were soaked in concentrated $\mathrm{H}_{2} \mathrm{SO}_{4}$ for about $5 \mathrm{~h}$, denoted as PEDOT:PSS-SA and $\mathrm{M}: \mathrm{P}=10: 1-\mathrm{SA}$.

FT-IR spectra of PEDOT:PSS and the composite films of M:P=10:1 are shown in Figure S4A. The PEDOT:PSS spectrum shows a strong peak at $1367 \mathrm{~cm}^{-1}$ which is attributed to the aromatic ring vibration in the thiophene ring. Bands at $1261 \mathrm{~cm}^{-1}$ are attributed to the $\mathrm{C}-\mathrm{O}-\mathrm{C}$ stretching modes and the peak at $858 \mathrm{~cm}^{-1}$ is related to $\mathrm{C}-\mathrm{S}$ stretching vibration of the EDOT ring. The peaks at 1124 and $1161 \mathrm{~cm}^{-1}$ are attributed to the stretching vibrations of the merged aromatic ring of PSS. Here we use the peak of $1261 \mathrm{~cm}^{-1}$ belonging to PEDOT as a standard to compare the contention of PSS before and after treatment with concentrated $\mathrm{H}_{2} \mathrm{SO}_{4}$. It is shown that the $\mathrm{H}_{2} \mathrm{SO}_{4}$ treatment induces a change in the PEDOT:PSS composition ratio, which is revealed by the different transmittance observed for the different samples. After the $\mathrm{H}_{2} \mathrm{SO}_{4}$ treatment, the peak intensity at $1161 \mathrm{~cm}^{-1}$ is significantly reduced, whereas the peak at $1261 \mathrm{~cm}^{-1}$ exhibits almost no change. These observations clearly demonstrate that the $\mathrm{H}_{2} \mathrm{SO}_{4}$ treatment induces the selective removal of PSS without influencing the PEDOT part in PEDOT:PSS. When the $\mathrm{M}: \mathrm{P}=10: 1$ is treated, the peak intensity at $1161 \mathrm{~cm}^{-1}$ decreases further than the treated PEDOT:PSS, which means that more PSS is being removed. This conclusion is in consistent with the weight loss after treatment.

The PEDOT/PSS ratio change after $\mathrm{H}_{2} \mathrm{SO}_{4}$ treatment is also revealed by the absorption spectra. As shown in Figure S4B, the strong absorption features in the UV range are attributed to the phenyl moieties in PSS, and the broad absorption band in the visible and IR regions is associated with the free charge carriers in PEDOT. ${ }^{[1]}$ After the $\mathrm{H}_{2} \mathrm{SO}_{4}$ treatment, two strong absorption peaks in the UV range are significantly reduced, whereas the absorption features with a lower 


\section{WILEY-VCH}

energy (>500 nm) exhibit almost no change. These observations clearly demonstrate that the $\mathrm{H}_{2} \mathrm{SO}_{4}$ treatment induces the selective removal of PSS without influencing the PEDOT part in PEDOT:PSS. For M:P=10:1, when treated with $\mathrm{H}_{2} \mathrm{SO}_{4}$, a more prominent reduction of the peak in the UV region can be seen comparing to treated PEDOT:PSS. Combining the FT-IR and absorption spectra, we conclude that the PEDOT to PSS ratio in the treated composite film is larger than the treated PEDOT:PSS.

From previous report, a certain amount of negatively charged PSS is necessary for the charge balance of the positively charged PEDOT, and for the formation of the highly crystalline form of PEDOT:PSS (PEDOT/PSS ratio 2) upon $\mathrm{H}_{2} \mathrm{SO}_{4}$ treatment. ${ }^{[2]}$ In the current study, we don't observe the formation of the highly crystalline form of PEDOT:PSS based on XRD, likely due to the large PEDOT:PSS ratio (PEDOT/PSS ratio >2) in the composite. We speculate that the presumed negatively charged MXene may, at least in part, take the role of PSS, so most of the PSS is removed from the composite film after $\mathrm{H}_{2} \mathrm{SO}_{4}$ treatment.
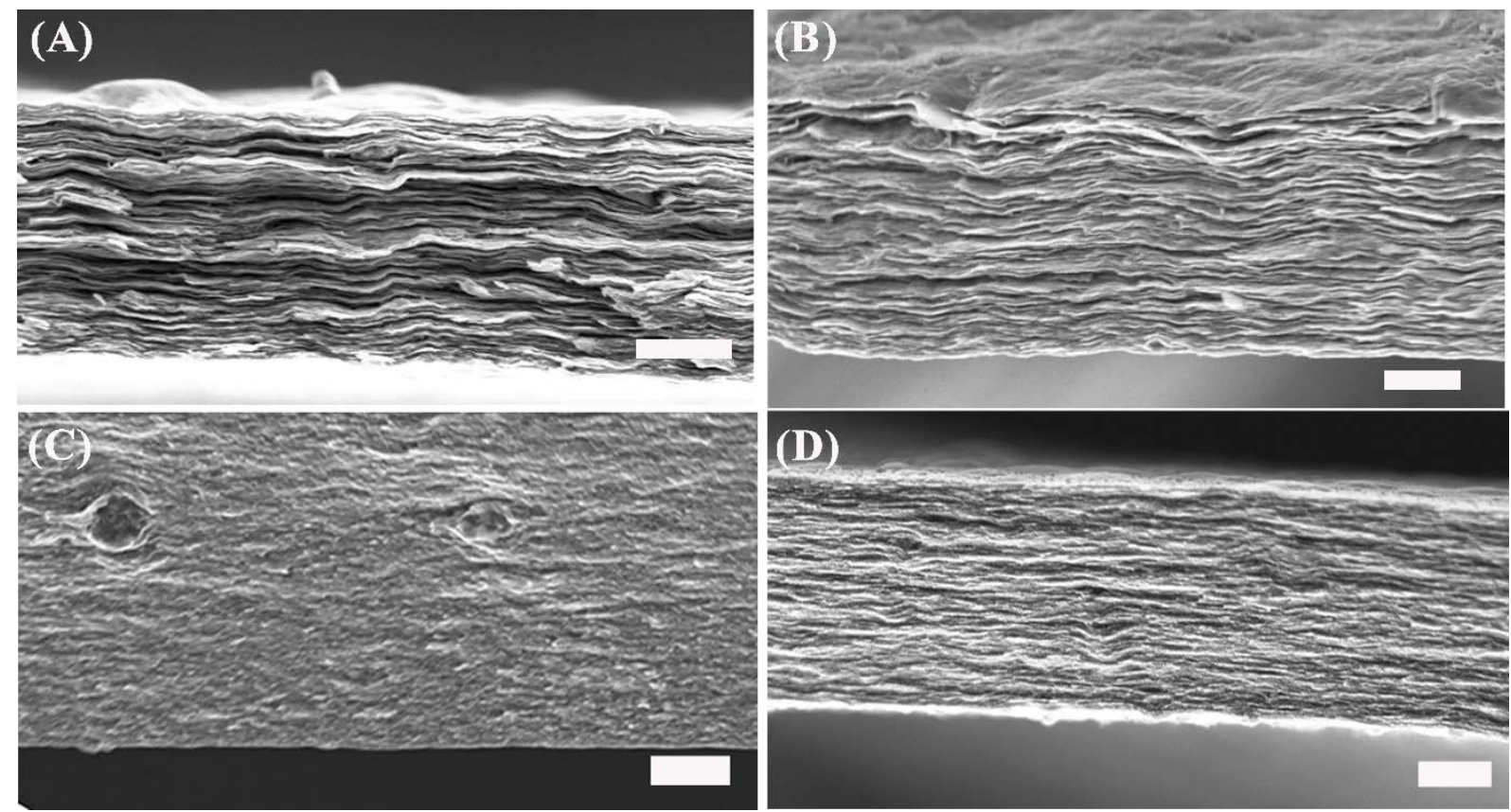

Figure S4. Cross-sectional SEM image of (A) pristine Mo1.33C, (B) Mo1.33C-24h, (C) PH1000 and (D) PH1000-24h (scale bar: $1 \mu \mathrm{m}$ ). 


\section{WILEY-VCH}
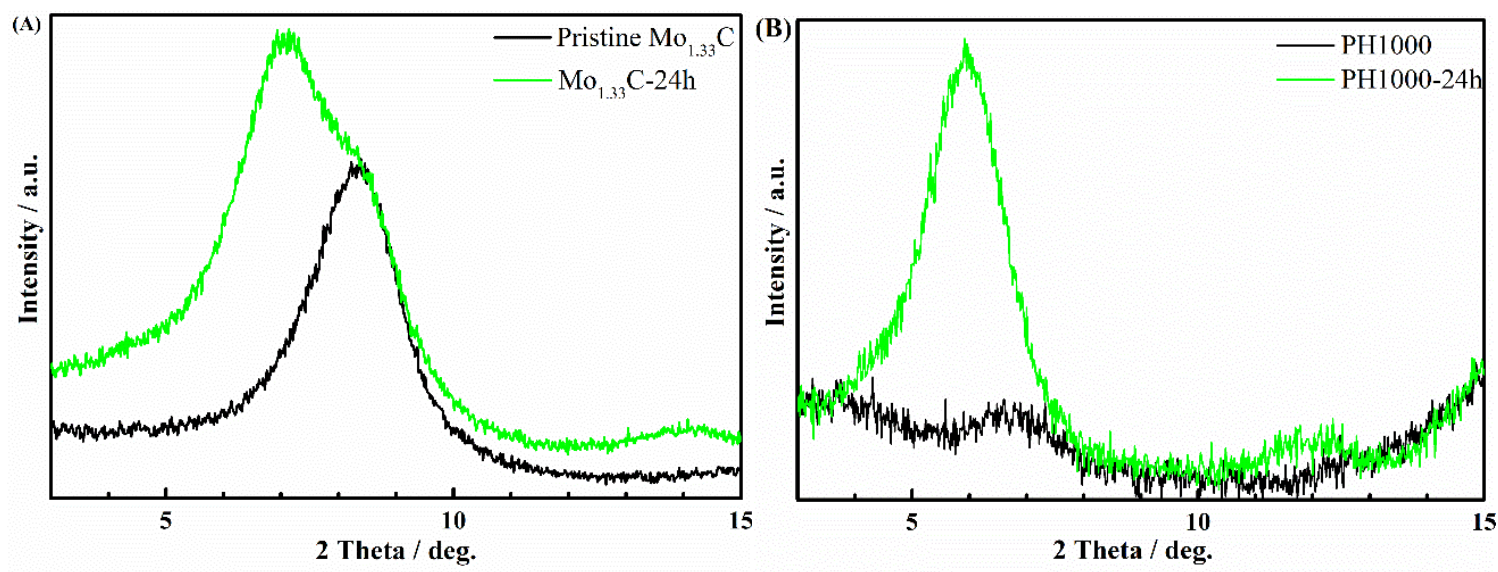

Figure S5. XRD pattern of (A) pristine $\mathrm{Mo}_{1.33} \mathrm{C}$ and $\mathrm{Mo}_{1.33} \mathrm{C}-24 \mathrm{~h},(\mathrm{~B}) \mathrm{PH} 1000$ and PH100024h.

At the same time we also study the change of pristine $\mathrm{Mo}_{1.33} \mathrm{C}$ and PEDOT:PSS after treatment by concentrated $\mathrm{H}_{2} \mathrm{SO}_{4}$. For $\mathrm{Mo}_{1.33} \mathrm{C}$, as shown in the scanning electron microscopy (SEM) images (Figure S4A and B), the $\mathrm{Mo}_{1.33} \mathrm{C}$ maintains the layered structure after treatment. In addition, the X-ray diffraction (XRD) patterns (Figure S5A) of the pristine $\mathrm{Mo}_{1.33} \mathrm{C}$ film show a major peak at $8.4^{\circ}$. The $\mathrm{Mo}_{1.33} \mathrm{C}$ films treated with concentrated $\mathrm{H}_{2} \mathrm{SO}_{4}$ for 24 hours $\left(\mathrm{Mo}_{1.33} \mathrm{C}\right.$ -24h) exhibit a clear shift in the (001) peak from $\sim 8.4^{\circ}$ to $\sim 7.1^{\circ}$, indicating an increase in the spacing between the $\mathrm{Mo}_{1.33} \mathrm{C}$ sheets. This shift may be attributed to water or proton intercalation. Table 1 (in the manuscript) shows that the capacitance of $\mathrm{Mo}_{1.33} \mathrm{C}$ after treatment with concentrated $\mathrm{H}_{2} \mathrm{SO}_{4}$ only display a small drop compared to untreated $\mathrm{Mo}_{1.33} \mathrm{C}$.

The cross-sections of the PH1000 and PH1000-24h are imaged by SEM and shown in Figure S4C and D. The PH1000 film displays a uniform compact section, with no clear microstructure. However, after treatment with concentrated $\mathrm{H}_{2} \mathrm{SO}_{4}$ for 24 hours, the PH1000-24h film displays a laminated structure. This can be attributed to an excessive amount of uncoupled PSS being removed by $\mathrm{H}_{2} \mathrm{SO}_{4}$. In this process, the strong $\pi-\pi$ stacking of PEDOT and the rigidity of its backbone induce dense PEDOT networks with significant changes in both the crystallographic and morphological structures via the formation of a crystalline nanofibril laminated structure. The XRD patterns (Figure S5B) of PH1000-24h film shows a major sharp peak at $6^{\circ}$, however the untreated PH1000 did not show clear peak, which indicates that concentrated $\mathrm{H}_{2} \mathrm{SO}_{4}$ 


\section{WILEY-VCH}

treatment significantly improved the crystallinity of the PH1000 films. This is consistent with the results from SEM. In addition, after treatment with concentrated $\mathrm{H}_{2} \mathrm{SO}_{4}$, the capacitance of PH1000-24h was significantly improved compared to PH1000 (Table 1 in the manuscript). The above results show that the treatment with concentrated $\mathrm{H}_{2} \mathrm{SO}_{4}$ has little effect on $\mathrm{Mo}_{1.33} \mathrm{C}$, but significantly improves the crystallinity and capacitance of PH1000.

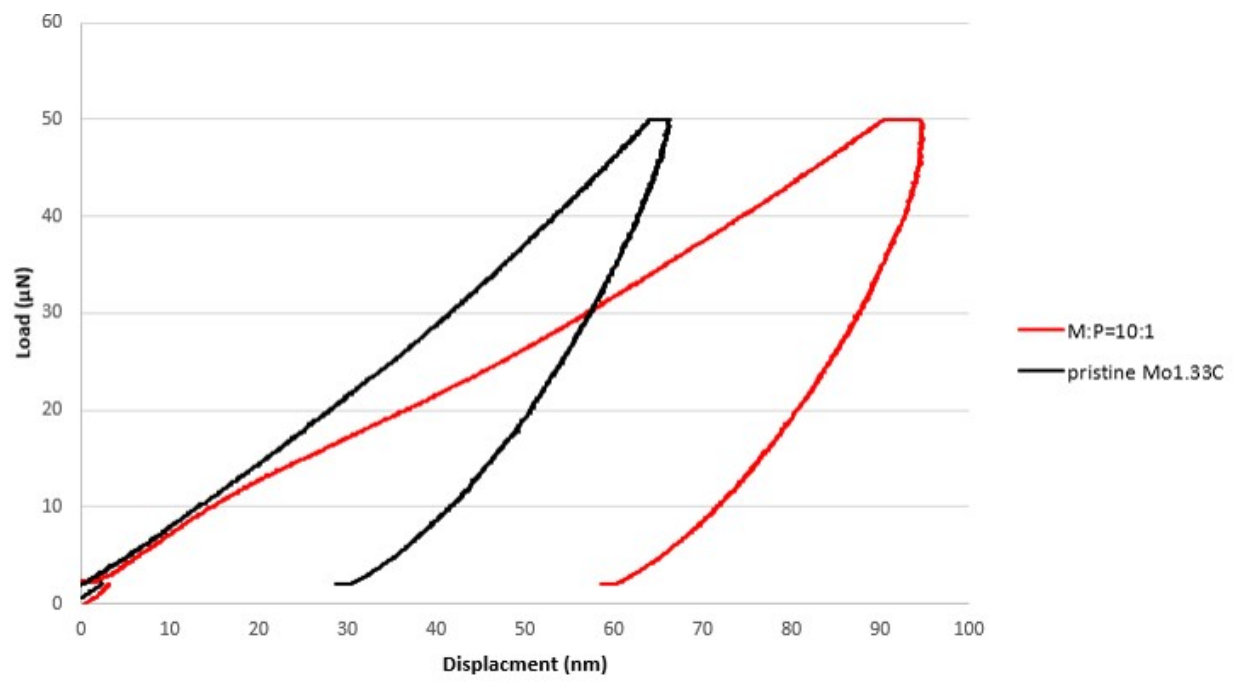

Figure S6. The mechanical properties of the $\mathrm{Mo}_{1.33} \mathrm{C}$ and composite film.

Table S1. The electrical conductivity of pristine $\mathrm{Mo}_{1.33} \mathrm{C}$ and composite film was measured with a 4-point-probe.

We are aware of the limitations of this technique for analysis of composite materials, however, for the present study we focus on the qualitative trend in conductivity before/after $\mathrm{H}_{2} \mathrm{SO}_{4}$ treatment.

\begin{tabular}{|c|c|c|c|}
\hline & Pristine $\mathrm{Mo}_{1.33} \mathrm{C}$ & $\mathrm{M}: \mathrm{P}=10: 1$ & $\mathrm{M}: \mathrm{P}=10: 1-24 \mathrm{~h}$ \\
\hline $\begin{array}{c}\sigma \\
{\left[\mathrm{S} \mathrm{m}^{-1}\right]}\end{array}$ & $129^{\mathrm{a})}$ & 121 & 1843 \\
\hline
\end{tabular}

a) The high conductivity (29674 S m${ }^{-1}$ ) of $\mathrm{Mo}_{1.33} \mathrm{C}$ reported by Tao etc. ${ }^{[3]}$ was measured with a Physical Property Measurement System (Quantum Design, San Diego). Here, four-point probe (Jandel RM3000 Resistivity Meter) was used to measure the RT resistivity of the composite films and pristine $\mathrm{Mo}_{1.33} \mathrm{C}$. 


\section{WILEY-VCH}
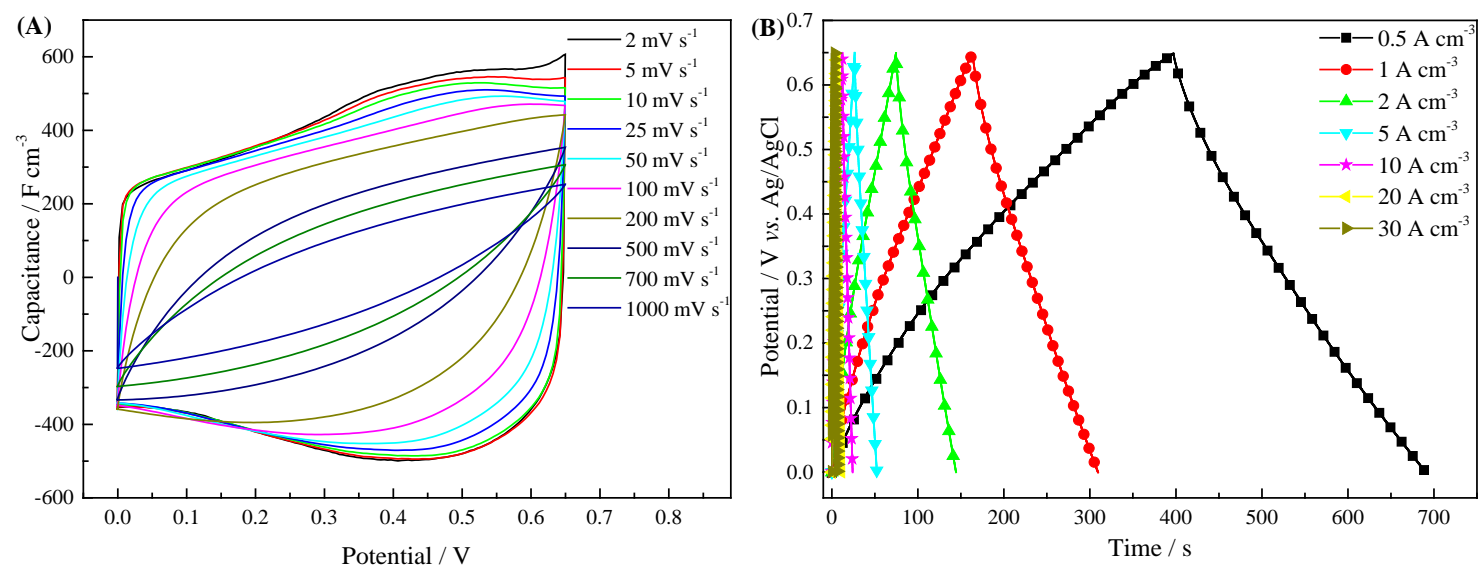

Figure S7. (A) Cyclic voltammetry (CV) profiles of the device (pristine MXene) obtained at different scanning rates. (B) Galvanostatic charge/discharge (GCD) curves of the device (pristine MXene) at different current densities.
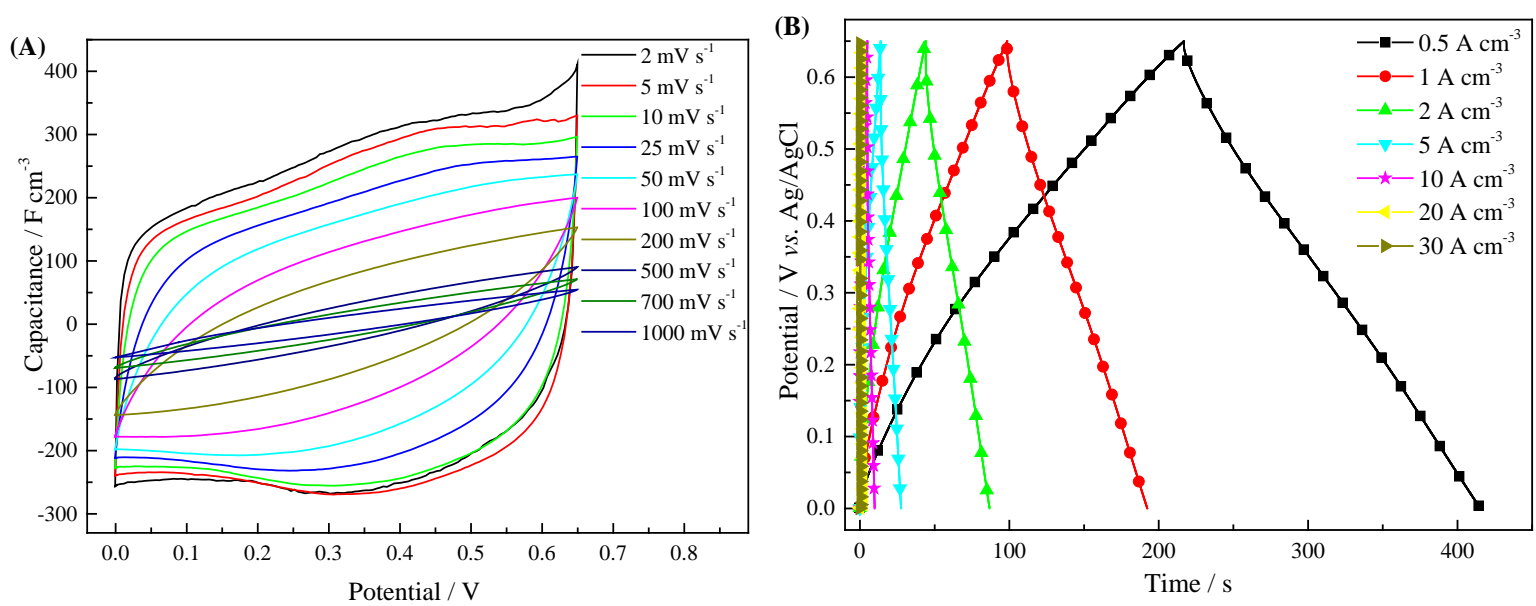

Figure S8. (A) Cyclic voltammetry (CV) profiles of the device (M:P=10:1) obtained at different scanning rates. (B) Galvanostatic charge/discharge (GCD) curves of the device (M:P=10:1) at different current densities. 


\section{WILEY-VCH}
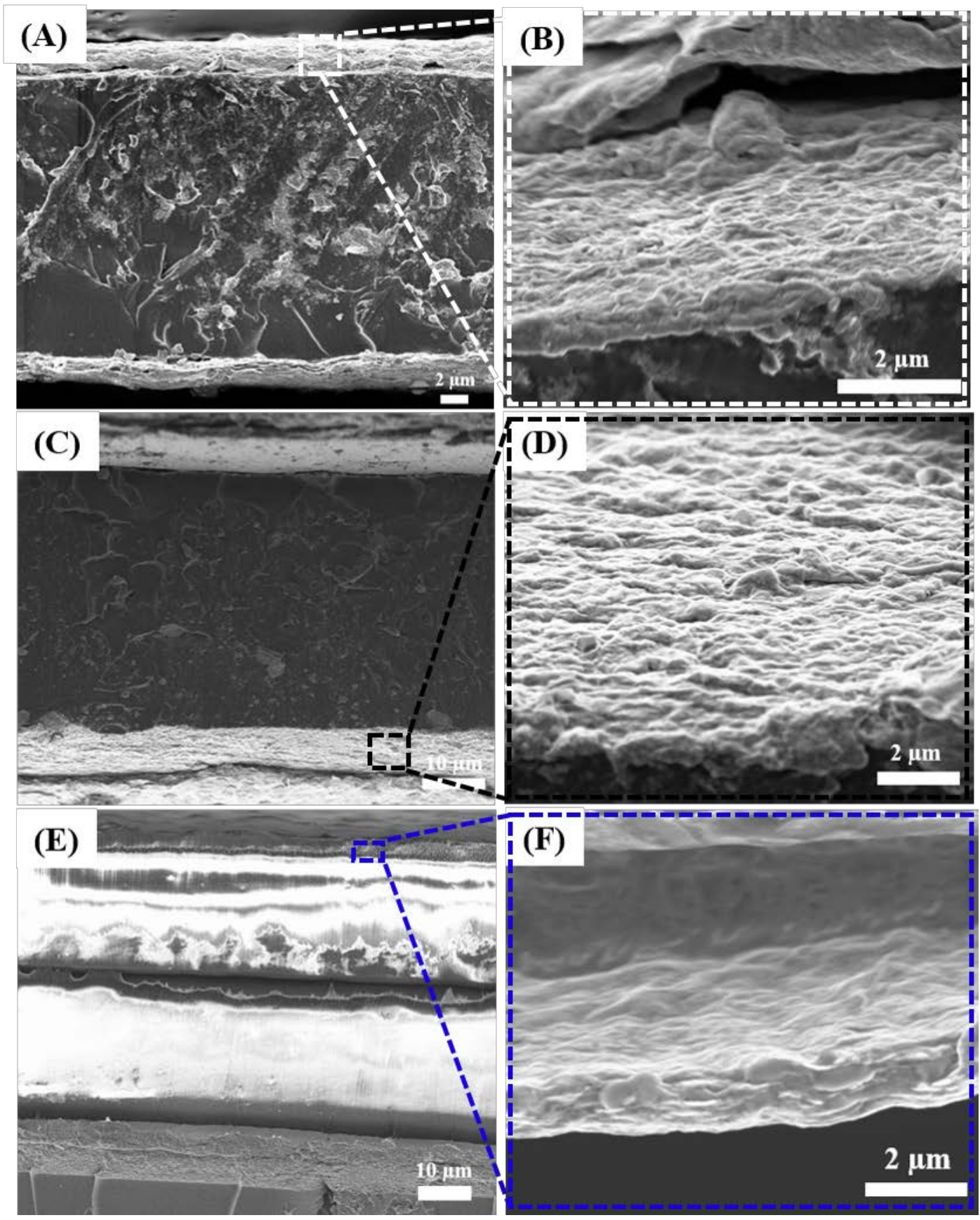

Figure S9. Cross-sectional SEM image of the device after cycling test. (A) $M: P=10: 1-24 h$, (C) $\mathrm{M}: \mathrm{P}=10: 1$ and $(\mathrm{E})$ pristine $\mathrm{Mo}_{1.33} \mathrm{C}$. The left side SEM image (B, D and F) is an enlarged view of the active materials part of the device. 


\section{WILEY-VCH}

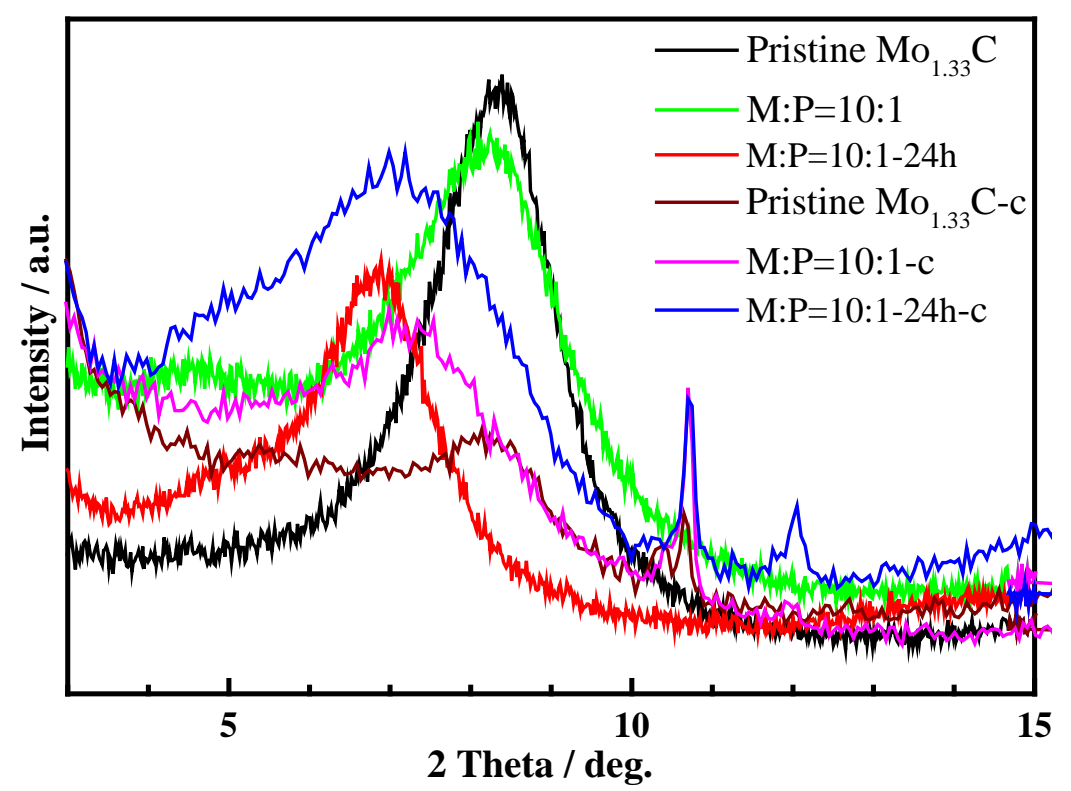

Figure S10. XRD patterns of the films (before cycling) and devices after cycling.

After cycling, the $\mathrm{Mo}_{1.33} \mathrm{C}$ MXene/PEDOT:PSS devices were studied with SEM (Figure S9) and XRD (Figure S10, which also includes the three films before cycling for comparison). Figure S9 shows cross-sectional SEM image of the device ((A) $\mathrm{M}: \mathrm{P}=10: 1-24 \mathrm{~h},(\mathrm{C}) \mathrm{M}: \mathrm{P}=10: 1$ and (E) pristine $\mathrm{Mo}_{1.33} \mathrm{C}$ ), respectively. After 10000 cycles, the morphology of the $\mathrm{M}: \mathrm{P}=10: 1-$ 24h and M:P=10:1 films (Figure S9B and D) almost maintain the aligned structures to those before the cycling, indicating that the $\mathrm{Mo}_{1.33} \mathrm{C}$ were effectively stabilized by the PEDOT nanofiber network. However, the layered structure of the pristine $\mathrm{Mo}_{1.33} \mathrm{C}$ disappeared as shown in Figure S9F, indicated that the morphology of the pristine $\mathrm{Mo}_{1.33} \mathrm{C}$ film significantly changed. The XRD patterns (Figure S10) of the pristine $\mathrm{Mo}_{1.33} \mathrm{C}$ after cycling (Pristine $\mathrm{Mo}_{1.33} \mathrm{C}-\mathrm{c}$ ) shows a reduced peak at 8 degrees, which indicates that the order of $\mathrm{Mo}_{1.33} \mathrm{C}$ has decreased. Also, the main peak for $\mathrm{M}: \mathrm{P}=10: 1-24 \mathrm{~h}$ did not shift, suggesting a stable interlayer distance. Furthermore, a new peak appeared at 10.8 degrees for all devices after cycling, which may originate from oxidation of some of the $\mathrm{Mo}_{1.33} \mathrm{C}$ MXene, to form $\mathrm{MoO}_{\mathrm{x}}$, during the cycling. The above data suggest that the stabilization of the composite film may be attributed to the constraint of intercalated PEDOT nanofiber network during the cycling process and the strong bond with the $\mathrm{Mo}_{1.33} \mathrm{C}$ sheets. 


\section{WILEY-VCH}

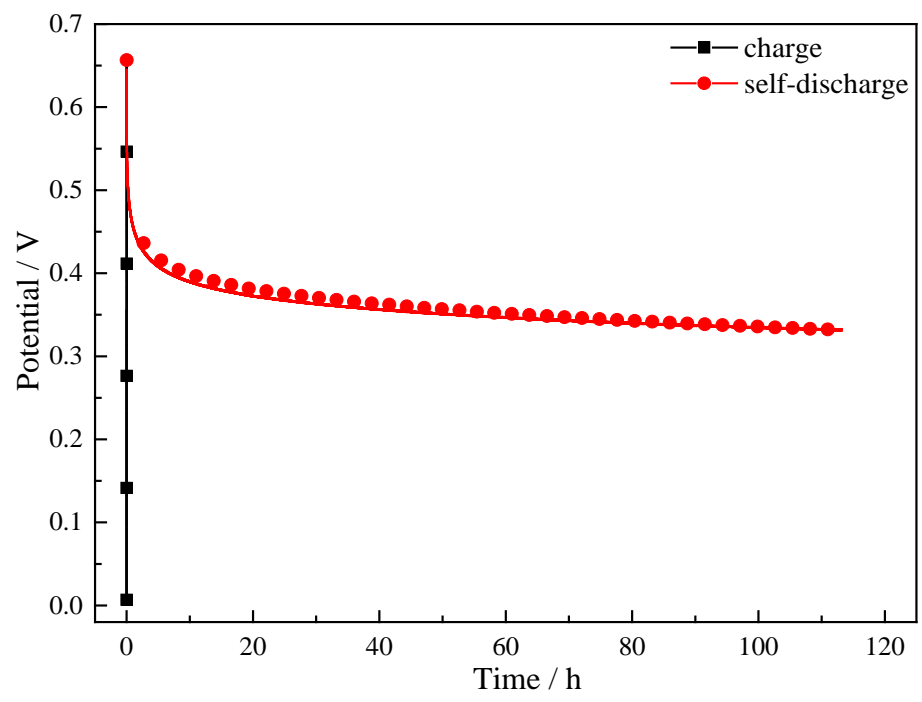

Figure S11. Self-discharge behaviour of $\mathrm{M}: \mathrm{P}=10: 1-24 \mathrm{~h}$ composite device.
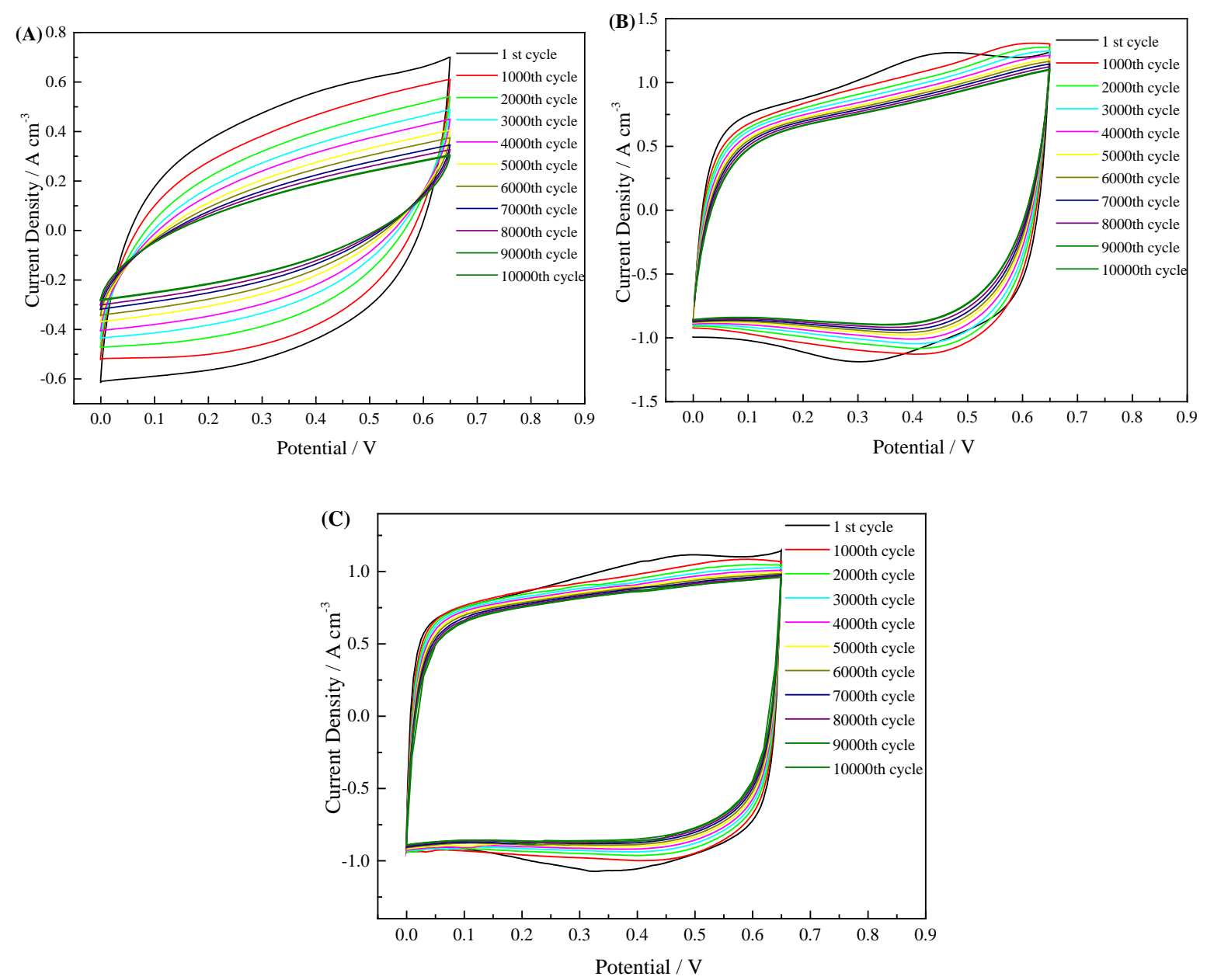

Figure S12. The cycling stability of the fabricated all-solid-state supercapacitors by $\mathrm{CV}$ at the scan rate of $100 \mathrm{mV} \mathrm{s}^{-1}$. (A) Pristine $\mathrm{Mo}_{1.33}$ C. (B) $\mathrm{M}: \mathrm{P}=10: 1$. (C) $\mathrm{M}: \mathrm{P}=10: 1-24 \mathrm{~h}$. 


\section{WILEY-VCH}
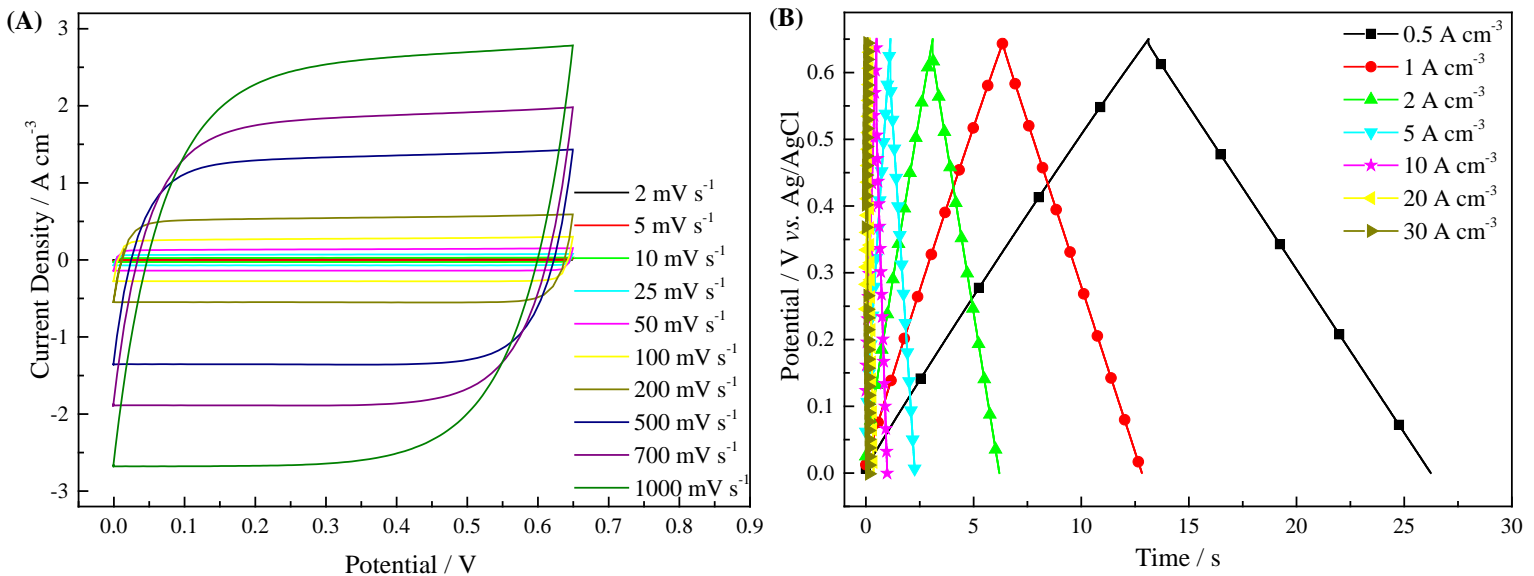

Figure S13. (A) Cyclic voltammetry (CV) profiles of PH1000 device obtained at different scanning rates. (B) Galvanostatic charge/discharge (GCD) curves of PH1000 device at different current densities.
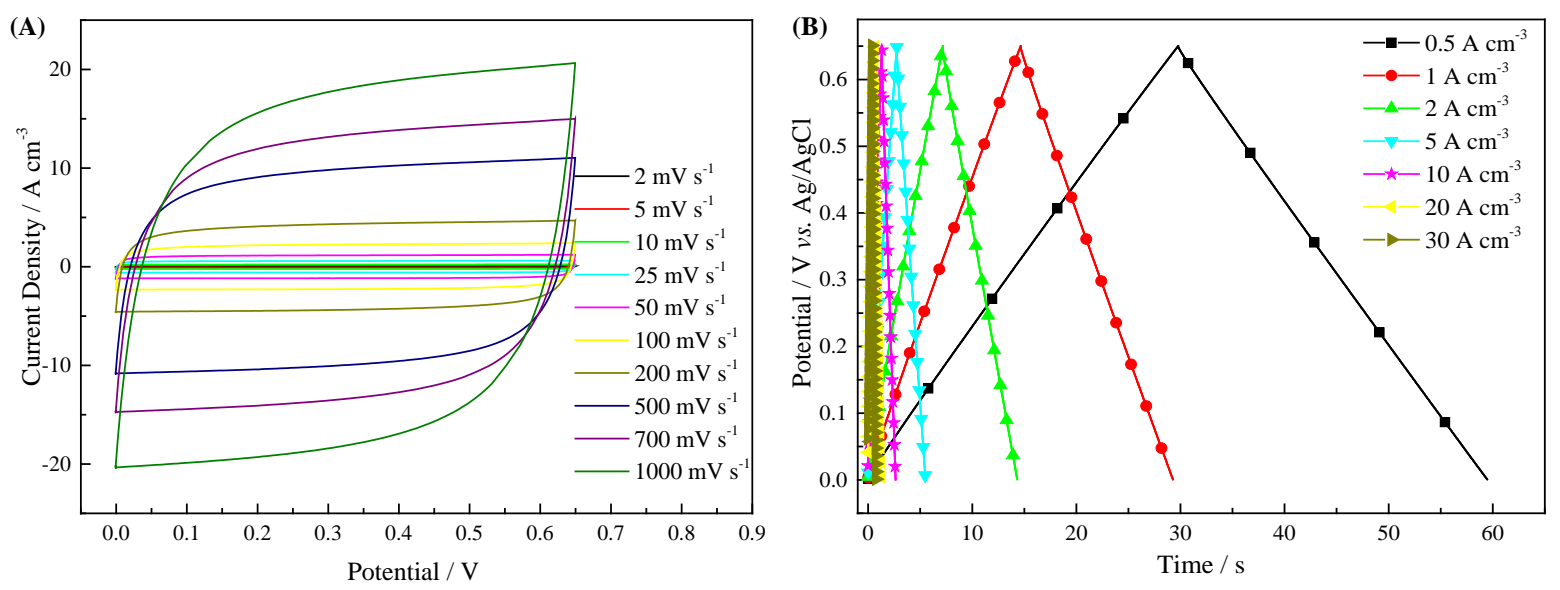

Figure S14. (A) Cyclic voltammetry (CV) profiles of PH1000-24h device obtained at different scanning rates. (B) Galvanostatic charge/discharge (GCD) curves of PH1000-24h device at different current densities.

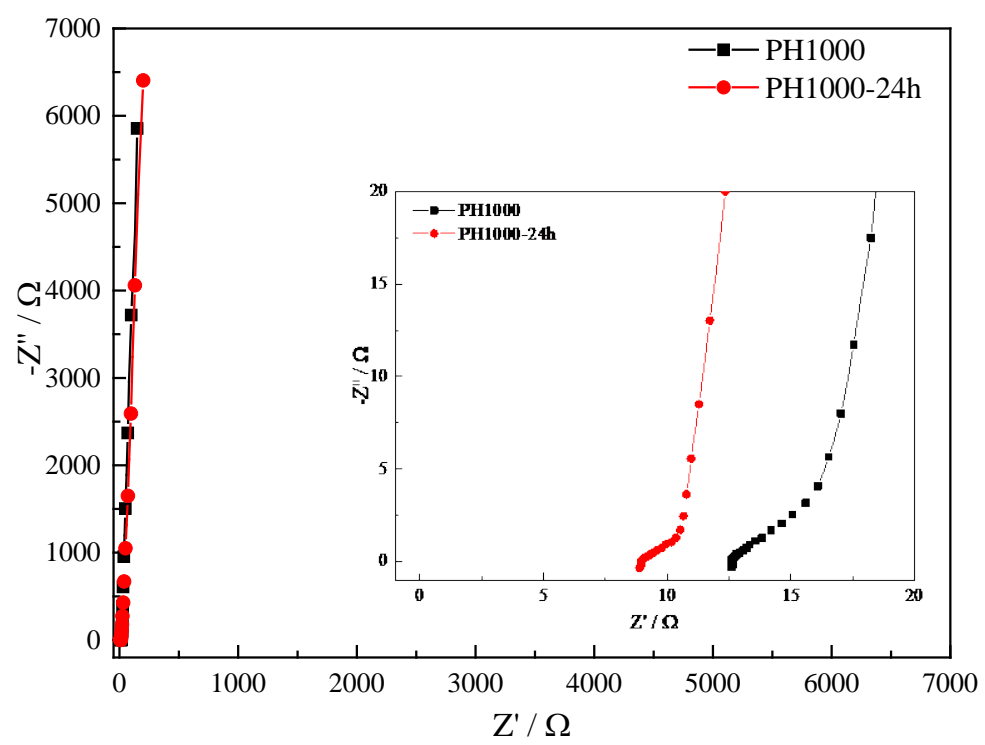




\section{WILEY-VCH}

Figure S15. Nyquist plot of the device tested at the open-circuit potential within the frequency range from $10^{-2}$ to $10^{5} \mathrm{~Hz}$. The inset shows the enlarged plot in the high frequency region.

Reference:

1. L. A. A. Pettersson, S. Ghosh, O. Inganäs, Org. Electron. 2002, 3, 143.

2. N. Kim, S. Kee, S. H. Lee, B. H. Lee, Y. H. Kahng, Y.-R. Jo, B.-J. Kim, K. Lee, Adv. Mater. 2014, 26, 2268.

3. Q. Tao, M. Dahlqvist, J. Lu, S. Kota, R. Meshkian, J. Halim, J. Palisaitis, L. Hultman, M. W. Barsoum, P. O. Å. Persson, J. Rosen, Nat. Commun. 2017, 8, 14949. 